Check for updates

Cite this: RSC Adv., 2018, 8, 38289

\section{Synthesis and anticancer studies of Michael adducts and Heck arylation products of sesquiterpene lactones, zaluzanin $D$ and zaluzanin $C$ from Vernonia arborea $\dagger$}

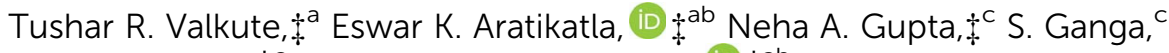 \\ Manas K. Santra*c and Asish K. Bhattacharya (D)*ab
}

Sesquiterpene lactones containing $\alpha$-methylene- $\boldsymbol{\gamma}$-lactones, zaluzanin D 1 and zaluzanin $C 2$ were isolated from the leaves of Vernonia arborea. Several diverse Michael adducts (3-22) and Heck arylation analogs (23-34) of 1 have been synthesized by reacting with various amines and aryl iodides, respectively and were assayed for their in vitro anticancer activities against human breast cancer cell lines MCF7 and MDA-MB-231. Among all the synthesized analogs, Michael adducts 9 and 10 showed better anticancer activities as compared to 1 . However, among these compounds, only 10 has minimal cytotoxic effect on normal breast epithelial MCF10A cells. Our detailed mechanistic studies reveal that compounds 9 and 10 execute their antiproliferative activity through induction of apoptosis and thereby inhibit the cancer cells proliferation and compound 10 could be a lead compound for designing potential anti-cancer compound.
Received 23rd July 2018

Accepted 3rd November 2018

DOI: $10.1039 / \mathrm{c} 8 \mathrm{ra0} 238 \mathrm{~b}$

rsc.li/rsc-advances
To overcome this, amino-adducts of sesquiterpene lactones have been prepared by adding different amines to the $\alpha$-methylene- $\gamma$-lactone substructure to enhance the water solubility of the parent molecules and to retain their biological activity., Regeneration of parent $\alpha, \beta$-unsaturated $\gamma$-lactone occurs by the retro-Michael reaction, potentially through bioactivation at the site of action. This prodrug approach has transformed several sesquiterpene lactones such as alantolactone, ambrosin, arglabin, costunolide, helenalin, parthenolide and ivangustin, into successful clinical candidates (Fig. 1). ${ }^{8}$

Continuing our interest in naturally occurring sesquiterpene lactones ${ }^{9}$ and other bioactive secondary metabolites, we wished to take up the chemical examination of $V$. arborea leaves for the isolation of bioactive secondary metabolites, zaluzanin $\mathrm{C}$ and zaluzanin D. In the present study, several structurally diverse Michael adducts of zaluzanin $\mathrm{D}$ have been synthesized with the formation of one or two new $\mathrm{C}-\mathrm{N}$ bonds. Analogs of zaluzanin $\mathrm{D}$ with a new $\mathrm{C}-\mathrm{C}$ bond formation have also been synthesized by using Pd catalyzed Heck coupling reaction. The in vitro anticancer activities of all the analogs were tested against human breast cancer cell lines MCF7 and MDA-MB-231.

\section{Results and discussion}

A portion of the petroleum ether extract $(5.3 \mathrm{~g})$ was flash chromatographed on CombiFlash Companion, Isco Teledyne Inc., USA using $\operatorname{RediSep}{ }^{\circledR}$ column $\left(\mathrm{SiO}_{2}, 2 \times 12 \mathrm{~g}\right)$ and elution was carried out isocratically with ethyl acetate-petroleum ether ( $4: 96)$ to furnish a colorless solid. It was identified as zaluzanin 
<smiles>C=C(C)C(=O)O[C@H]1C[C@H](OC(C)=O)CCC(C)(C)[C@H]2O[C@H]1C2=C(CO)C(=O)O</smiles>

$\mathrm{R}=\mathrm{Ac}$, Glaucolide $\mathrm{K}$ $\mathrm{R}=\mathrm{H}$, Glaucolide L<smiles>C=C[C@]12COC(=O)C(=C)[C@@H]1C(=C)C(=O)OC2</smiles>

Vernolepin<smiles>C=C[C@]12COC(=O)C(=C)[C@H]1[C@@H](O)C1C(=C)C(=O)O[C@@H]1C2</smiles>

Vernomenin<smiles>C=C(CO)C(=O)O[C@H]1CC(=C)[C@H]2CC[C@@H](CO)[C@]2(C)[C@H]2OC(=O)C(=C)[C@@H]12</smiles>

Vernonilide A<smiles>C=C(CO)C(=O)O[C@H](CC1=CCCC(C=O)=CC1O)[C@@H]1C(=C)C(=O)O[C@@H]1C</smiles>

Vernopicrin<smiles>C=C[C@]1(C)C[C@H](OC(=O)C(=C)CO)[C@H]2C(=C)C(=O)O[C@H]2C1C(=C)CO</smiles>

Vernomelitensin

Fig. 1 Selected examples of sesquiterpene lactones isolated from genus Vernonia.

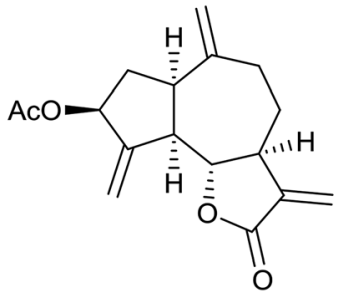

1

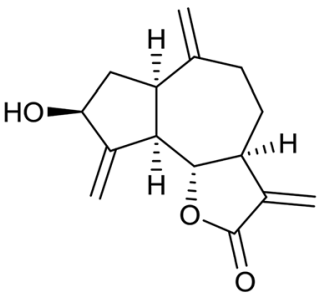

2
Fig. 2 Structures of zaluzanin D 1 and zaluzanin C 2 isolated from $V$. arborea.

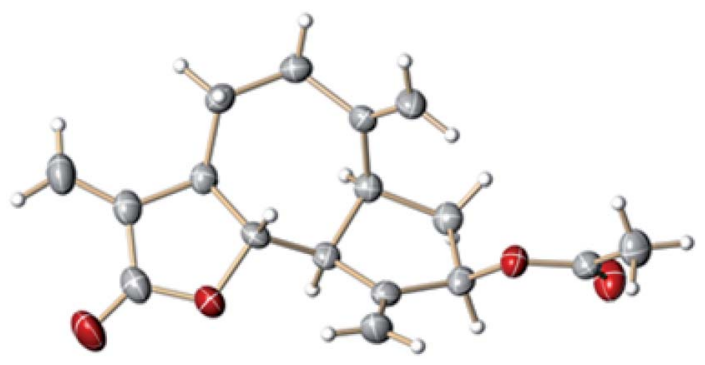

Fig. 3 ORTEP diagram of zaluzanin D 1.

D 1, a sesquiterpene lactone having guaianolide skeleton $(\alpha-$ methylene- $\gamma$-lactone) based on its NMR and HRMS spectra and comparison with an authentic sample ${ }^{\mathbf{1 0}}$ (Fig. 2). Further flash chromatography with ethyl acetate-petroleum ether (6:94) furnished zaluzanin C 2. Finally, we proved the structure of zaluzanin D 1 by its single crystal X-ray analysis (Fig. 3). ${ }^{11}$
Both these compounds were assayed against human breast cancer cell line, MCF7 and zaluzanin D 1 exhibited an $\mathrm{IC}_{50}$ value of $53.7 \mu \mathrm{M}$ whereas zaluzanin $\mathrm{C} 2$ was found to be inactive (Table 2).

\section{Synthesis of Michael adducts of zaluzanin D using different chiral/achiral amines}

Since Michael addition of primary or secondary amines to $\alpha, \beta$ unsaturated lactones resulted in the compounds possessing higher anticancer activities compared to the original compound, ${ }^{7,8}$ we wished to synthesize a library of amino adducts of zaluzanin $\mathrm{D}$ with one or more new $\mathrm{C}-\mathrm{N}$ bonds. The amino derivatives of zaluzanin D 1 were synthesized via Michael addition of different amines to the $\alpha, \beta$-unsaturated $\gamma$-lactone functionality present in zaluzanin D. As shown in Scheme 1, a methanolic solution of chiral/achiral amine and zaluzanin D underwent Michael addition at room temperature to furnish various Michael adducts of zaluzanin D, 3-22 (Table 1). Michael addition of chiral amine $(S)-(-)-\alpha$-methylbenzylamine to zaluzanin D furnished a mixture of two products, compound 3 and its corresponding deacetylated product 4 (entry 1, Table 1) which were isolated by flash chromatography. The formation of deacetylated product 4 may be due to the in situ formation of zaluzanin C, which in turn formed due to the basicity of amine, used in the Michael addition.

Addition of the amine to zaluzanin D was found to be diastereoselective, and the stereochemistry of C-11 in compound 3 was assigned $^{\mathbf{1 2}}$ as $\alpha$ by its NOESY experiment. In the NOESY spectra of compound 3, correlations were observed between $6 \beta$ $\mathrm{H}$ and $11 \beta-\mathrm{H}$. Also, $5 \alpha-\mathrm{H}$ showed a correlation with $7 \alpha-\mathrm{H}$ (Fig. 4). 


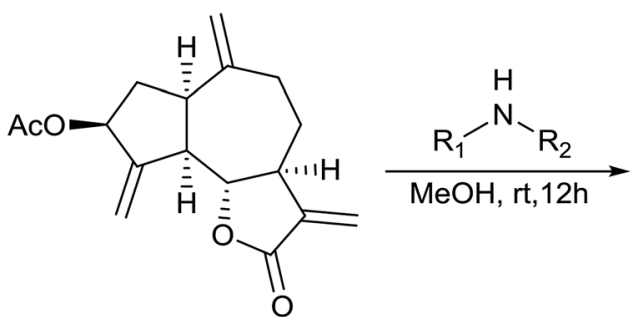

Zaluzanin D 1

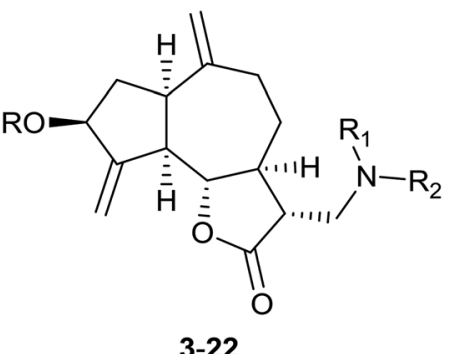

3-22

$\mathrm{R}=\mathrm{Ac}$ (or) $\mathrm{H}$

$\mathrm{R}_{1}=$ Aryl (or) Alkyl

$\mathrm{R}_{2}=$ Aryl (or) Alkyl (or) $\mathrm{H}$

Scheme 1 Synthesis of Michael adducts (3-22) of zaluzanin D 1.

Similarly, the reaction of zaluzanin D 1 with $(R)-(+)-\alpha$-methylbenzylamine resulted in the formation of compounds 5 and 6 . The reaction of zaluzanin D 1 with $(S)$ - and (R)-1-(1-naphthyl) ethylamine also furnished the compounds 7,8 and $\mathbf{9}, \mathbf{1 0}$ respectively (entries 3 and 4, Table 1). However, reaction with $(R)$ - and $(S)$-1-cyclohexylethylamine furnished the deacetylated product only (compounds 11 and 12, entries 5 and 6, Table 1). Next, we carried out the reaction of zaluzanin D 1 with various six and five-membered cyclic amines, which furnished corresponding $\mathrm{C}-\mathrm{N}$ derivatives of zaluzanin D 1 (entries 7-11, Table 1). 4-Hydroxypiperidine and morpholine on reaction with zaluzanin D 1 yielded acetylated products (13 and 17$)$ and deacetylated products (14 and 18), respectively (entries 7 and 9, respectively, Table 1). An interesting result was obtained in case of piperazine (entry 9, Table 1), which furnished acetylated dimer 15 and mono deacetylated dimer 16 with two new C-N bonds on both sides of piperazine. However, pyrrolidine and piperidine resulted in the formation of deacetylated products only (19 and 20, respectively) (entries 10 and 11, Table 1). Further, we tried to form a C-N bond of zaluzanin D 1 with amino acid methyl ester hydrochlorides (entries 12 and 13, Table 1). In this case, $\mathrm{K}_{2} \mathrm{CO}_{3}$ was used as a base for in situ generation of the free amine, which on reaction with zaluzanin D 1 furnished the deacetylated product 21. However, in case of valine methyl ester hydrochloride, excess use of $\mathrm{K}_{2} \mathrm{CO}_{3}$ resulted in the $\mathrm{C}-\mathrm{O}$ bond formed product $\mathbf{2 2}$.

\section{Synthesis of Heck arylated analogs of zaluzanin D using different aryl iodides (23-34)}

Although several structural modifications such as Michael addition, reduction, cyclopropanation of the double bond, oxidation of hydroxyl group of sesquiterpene lactones have been reported in literature, transition metal catalyzed cross coupling reactions of sesquiterpene lactones were less explored. ${ }^{13}$ We presumed that Heck arylation of $\alpha, \beta$-unsaturated $\gamma$-lactone core of zaluzanin D would provide additional information on structure-activity data of zaluzanin D. As shown in Scheme 2, Heck arylation analogs of zaluzanin $\mathrm{D}$ were synthesized using the standard Heck coupling conditions $\left(5 \mathrm{~mol} \% \mathrm{Pd}(\mathrm{OAc})_{2}, \mathrm{Et}_{3} \mathrm{~N}\right.$ in DMF at $80{ }^{\circ} \mathrm{C}$ ) and readily available aryl iodides.
It is pertinent to mention here that arylation preferred to take place at the exo-methylene of $\alpha, \beta$-unsaturated $\gamma$-lactone substructure over the other two isolated exo-methylene groups present in zaluzanin D $\mathbf{1}$ which resulted in the exclusive formation of $E$-olefin ${ }^{14}$ containing products only (Table 2).

\section{In vitro anticancer activities of Michael adducts of zaluzanin D (3-22)}

Since zaluzanin D 1 had exhibited anticancer activity against human breast cancer cell line (Table 3), we screened all the synthesized compounds for their antiproliferative activity against breast cancer cell line MCF7 and selected compound in MDA-MB-231. Cells were grown in the presence of different concentrations $(0-100 \mu \mathrm{M})$ of the synthesized compounds for $48 \mathrm{~h}$ and then MTT assay was performed as described in the experimental section. Among these compounds 1, 9, 10 and 14 showed activity $\left(\mathrm{IC}_{50}<50 \mu \mathrm{M}\right)$ against MCF7 and MDA-MB-231 (Table 3 and Fig. 5). Among these four compounds, $(R)-1-(1-$ naphthyl)ethylamine adducts of zaluzanin D and C (i.e. 9 and 10) were found to possess most potent antiproliferative effect (IC $\mathrm{I}_{50} 30 \mu \mathrm{M}$ and $18.8 \mu \mathrm{M}$, respectively) against MCF7 cells as compared to other synthesized compounds. Interestingly, compound 9 was found to possess more potent antiproliferative activity in highly metastatic MDA-MB-231 cell line $\left(\mathrm{IC}_{50} 13.33\right.$ $\mu \mathrm{M})$ as compared to MCF7 ( $\left.\mathrm{IC}_{50} 30 \mu \mathrm{M}\right)$ suggesting that 9 could be more effective in inducing cell death in higher grades of breast cancer. However, it also has potent cytotoxic effect on the normal breast epithelial MCF10A cells suggesting that compound 9 could not be useful for therapeutic purpose (Fig. 5c and Table 3). Interestingly, compound $\mathbf{1 0}$ has the minimal cytotoxic effect against the MCF10A suggesting that it could be a better candidate compound for further designing the small molecule to chemotherapy (Fig. $5 \mathrm{c}$ and Table 3). The in vitro anticancer activities of all the synthesized Michael adducts are depicted in Table 3.

To understand the inhibition of proliferation of cancer cells by these compounds, we have performed the FACS as described in the experimental section. Results showed that treatment of MCF7 cells with $\mathbf{9}$ and $\mathbf{1 0}$ significantly increased the apoptotic populations while compound $\mathbf{1}$ and $\mathbf{1 4}$ induced apoptosis to 
Table 1 Michael adducts of zaluzanin D (1) synthesized using various amines

Entry Amine Product(s)

1<smiles>CC(N)c1ccccc1</smiles><smiles>C[C@H](N)c1ccccc1</smiles><smiles>CC(N)c1cccc2ccccc12</smiles><smiles>C[C@H](N)c1cccc2ccccc12</smiles><smiles>C[C@H](N)C1CCCCC1</smiles><smiles>CC(N)C1CCCCC1</smiles><smiles>OC1CCNCC1</smiles>

8<smiles>C=C1CC[C@H]2[C@H](CN[C@H](C)c3ccccc3)C(=O)O[C@H]2[C@H]2C(=C)C(O)C[C@@H]12</smiles>

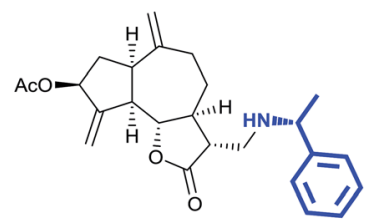

5

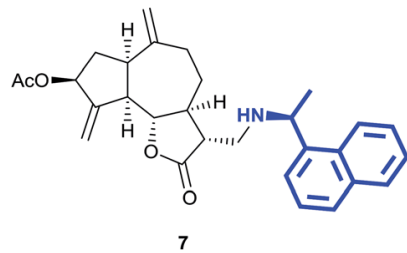<smiles>C=C1CC[C@H](CN[C@@H](C)c2cccc3ccccc23)[C@@H](CN[C@@H]2C(=O)O[C@H]3C(=C)C(OC(C)=O)C[C@H]23)C1</smiles>

-

-<smiles>C=C1CC[C@H](CN2CCC(O)CC2)[C@@H](C)C1C(=O)O</smiles>

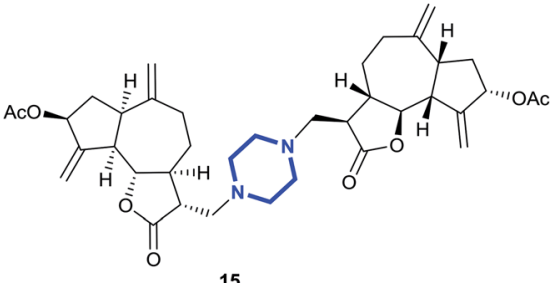<smiles>C=C1CC[C@H]2[C@H](CN[C@H](C)c3ccccc3)C(=O)O[C@H]2[C@H]2C(=C)C(O)C[C@@H]12</smiles><smiles>C=C1CC[C@H]2[C@H](CN[C@H](C)c3ccccc3)C(=O)O[C@H]2[C@H]2C(=C)C(O)C[C@@H]12</smiles><smiles>C=C1CC[C@H]2C(CN[C@H](C)c3cccc4ccccc34)C(=O)O[C@@H]2[C@H]2C(=C)C(O)C[C@@H]12</smiles><smiles>C=C1CC[C@@H]2[C@H](OC(=O)[C@H]2CN[C@H](C)c2cccc3ccccc23)[C@H]2C(=C)C(O)C[C@@H]12</smiles>

10<smiles>C=C1CC[C@@H]2[C@H](OC(=O)[C@H]2CN[C@H](C)C2CCCCC2)[C@H]2C(=C)C(O)C[C@@H]12</smiles>

11<smiles>C=C1CC[C@@H]2[C@H](OC(=O)[C@H]2CN[C@H](C)C2CCCCC2)[C@H]2C(=C)C(O)C[C@@H]12</smiles>

12<smiles>C=C1CC[C@H](CN2CCC(O)CC2)[C@H](CN2C(=O)O[C@H]3C(=C)C(O)C[C@@H]32)C1</smiles>

14

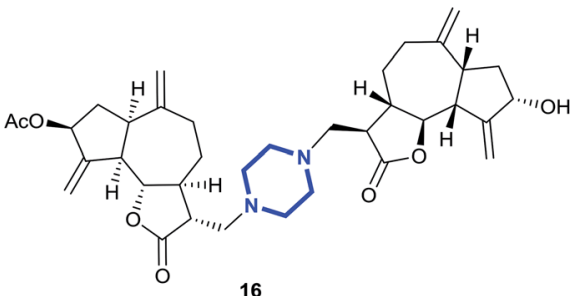


Table 1 (Contd.)

Entry Amine Product(s)

9<smiles>C1COCCN1</smiles>

10<smiles>C1CCNC1</smiles>

11

12<smiles>COC(=O)[C@H](N)CC(C)C</smiles><smiles></smiles>

13<smiles>C1CCNCC1</smiles>

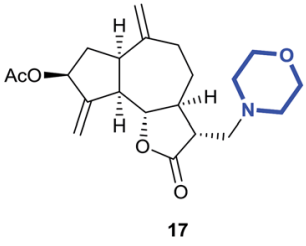

一

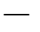

-

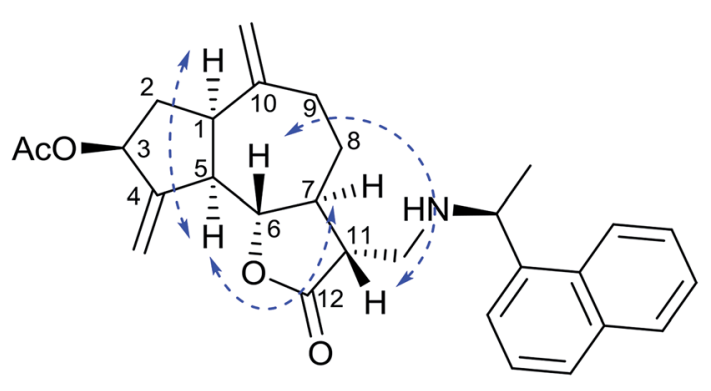

Fig. 4 NOE correlations of compound 3.

a lesser extent indicating that compounds $\mathbf{9}$ and $\mathbf{1 0}$ execute their antiproliferative activity through induction of apoptosis (Fig. 6a). To validate the apoptotic induction by these two compounds (9 and 10), we then checked fragmentation profile of genomic DNA following their treatment. ${ }^{15}$ Results demonstrated that the presence of substantial fragmented DNA ladder following treatment of MCF7 cells with these compounds (Fig. 6b). Similar results were also observed in vivo upon staining the DNA with Hoechst (Fig. 6c). Results taken together revealed that compound $\mathbf{9}$ and $\mathbf{1 0}$ are the potent inducer of apoptosis and thereby inhibits the cancer cells proliferation. We then checked the apoptotic pathway and found that $\mathbf{9}$ and $\mathbf{1 0}$ induced apoptosis through the intrinsic pathway of apoptosis through cleavage of caspase 9 (Fig. 6d). ${ }^{\mathbf{1 6}, 17}$ Collectively these results suggest that $\mathbf{9}$ and $\mathbf{1 0}$ may function as anticancer agents through induction of intrinsic apoptosis.

\section{In vitro anticancer activities of Heck analogs of zaluzanin $D$} (23-34)

All the synthesized Heck analogs 23-34 were assayed for their antiproliferative activity against breast cancer cell line MCF7 as described in experimental section. Among all the synthesized Heck analogs, two analogs, 31 and 32 exhibited good antiproliferative activity with $\mathrm{IC}_{50}$ values of 37 and $36.5 \mu \mathrm{M}$, respectively. Compound 29 showed moderate activity with $\mathrm{IC}_{50}$ 


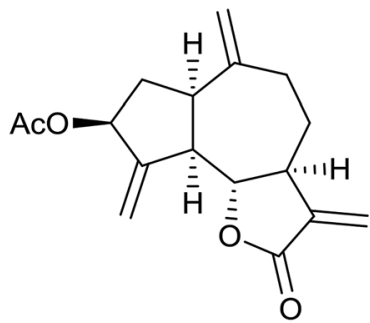

Zaluzanin D 1
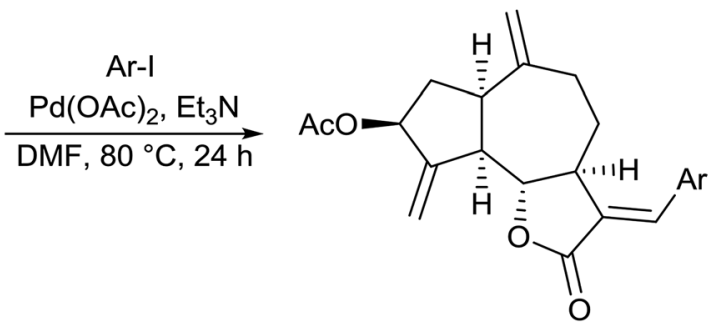

23-34

Scheme 2 Synthesis of Heck analogs of zaluzanin D 1.

value of $74 \mu \mathrm{M}$. The in vitro anticancer activities of all the synthesized Heck analogs are shown in Table 4.

\section{Conclusions}

In summary, we have isolated two guaianolide class of sesquiterpene lactones, zaluzanin D $\mathbf{1}$ and zaluzanin C $\mathbf{2}$ from the leaves of $V$. arborea. A library of several diverse Michael adducts (3-22) and Heck arylation analogs (23-34) of zaluzanin D 1 have been synthesized by reacting with various amines and aryl iodides, respectively. All the new functionalized molecules were assayed for their in vitro anticancer activities against human breast cancer cell lines MCF7 and MDA-MB-231 and selected compounds were checked in MCF10A. Isolated zaluzanin D 1 exhibited $\mathrm{IC}_{50}$ values of 53.7 and $34.17 \mu \mathrm{M}$ against MCF7 and MDA-MB-231 cell lines whereas zaluzanin C 2 was inactive to both the cell lines. Four Michael analogs $(9,10,13$ and 14) were found to possess potent anti-cancer activity as compared to other synthesized compounds. Out of these four compounds, compound $\mathbf{9}$ and $\mathbf{1 0}$ were found to exhibit potent antiproliferative effect against MCF7 cells. Compound 9 exhibited $\mathrm{IC}_{50}$ values of $30 \mu \mathrm{M}$ and $13.33 \mu \mathrm{M}$, whereas compound 10 exhibited $\mathrm{IC}_{50}$ values of $18.83 \mu \mathrm{M}$ and $23 \mu \mathrm{M}$ against MCF7 and MDA-MB-231 cell lines, respectively. However, compound 10 has minimal cytotoxic effect against the normal breast MCF10A cells indicating that compound $\mathbf{1 0}$ could be a potential compound for the development of superior anticancer therapeutic compound. Further, amongst all the synthesized Heck analogs 23-34, two analogs 31 and 32 exhibited good antiproliferative activity with $\mathrm{IC}_{50}$ values of 37 and $36.5 \mu \mathrm{M}$, respectively.

\section{Experimental section}

General

All melting points were recorded on a Büchi melting point apparatus in open capillaries and are uncorrected. Commercially available reagents and solvents were used as such received. Dry $\mathrm{MeOH}$ was prepared following the standard procedures. All dry reactions were carried out under an argon atmosphere, and flash chromatography was performed with CombiFlash $R_{\mathrm{f}} 200 i$ with UV/VIS and ELSD, Isco Teledyne Inc., USA using RediSep ${ }^{\circledR}$ column $\left(\mathrm{SiO}_{2}\right) .{ }^{1} \mathrm{H}$ NMR spectra were recorded on Bruker 500 or 400 or $200 \mathrm{MHz}$ spectrometers, and ${ }^{13} \mathrm{C}$ NMR spectra were recorded at 125 or 100 or $50 \mathrm{MHz}$, respectively. Chemical shifts are reported as $\delta$ values (ppm) relative to internal standard tetramethylsilane in $\mathrm{CDCl}_{3}$. HRMS (ESI) were recorded on an Orbitrap (quadrupole plus ion trap) and TOF mass analyzer. FT-IR spectra were recorded on an FTIR-8300 Shimadzu spectrometer. Optical rotations were recorded on a JASCO P-1020 polarimeter.

\section{Plant material}

The aerial parts of $V$. arborea were collected from the Kolli Hills (Perumakkai Shola), Tamilnadu, India during March 2013. The plant was identified by Prof. Dr N. Parthasarathy, Department of Ecology and Environmental Sciences, Pondicherry University, India where a voucher specimen (no. 5318) is being maintained.

\section{Extraction and isolation}

Air-dried and grounded leaves $(2.8 \mathrm{~kg})$ of $V$. arborea were extracted with petroleum ether $(5 \times 5.0 \mathrm{~L})$ at room temperature for five days. After completion of the extraction, the solvent was evaporated under reduced pressure to afford the petroleum ether extract (105 g). The remaining plant material was further extracted with $\mathrm{MeOH}(5 \times 5.0 \mathrm{~L})$ at room temperature for five days. After completion of the extraction, the solvent was evaporated under reduced pressure to afford the $\mathrm{MeOH}$ extract (224.15 g).

A portion of the petroleum ether extract $(5.3 \mathrm{~g})$ was flash chromatographed on CombiFlash Companion, Isco Teledyne Inc., USA using RediSep ${ }^{\circledR}$ column $\left(\mathrm{SiO}_{2}, 2 \times 12 \mathrm{~g}\right.$, stacked together) and isocratic elution was done with ethyl acetatepetroleum ether $(4: 96)$ to furnish the pure compound $(66.3 \mathrm{mg}$, $0.04 \%$ ) which was identified as zaluzanin D 1 on the basis of its spectral data, comparison of spectral data with reported data ${ }^{\mathbf{1 0}}$ and co-TLC with an authentic sample. Further flash chromatography with ethyl acetate-petroleum ether $(6: 94)$ furnished a pure compound, which was identified as zaluzanin C 2 $(16.3 \mathrm{mg}, 0.0098 \%)$ on the basis of its spectral data and comparison of spectral data with reported data. ${ }^{10}$

\section{Zaluzanin D (1)}

Colourless solid; $105-106{ }^{\circ} \mathrm{C}$ [reported ${ }^{10} 103-104{ }^{\circ} \mathrm{C}$ ]; $R_{\mathrm{f}} 0.35$ $(\mathrm{DCM}) ;[\alpha]_{\mathrm{D}}^{25}+23.5\left(\right.$ c $\left.1, \mathrm{CHCl}_{3}\right)\left[\right.$ reported $^{\mathbf{1 0}}+21.43$ (c 0.28 , $\left.\left.\mathrm{CHCl}_{3}\right)\right] ;{ }^{1} \mathrm{H} \mathrm{NMR}\left(200 \mathrm{MHz}, \mathrm{CDCl}_{3}\right) \delta_{\mathrm{H}} 6.22(\mathrm{~d}, J=3.5 \mathrm{~Hz}, 1 \mathrm{H})$, $5.63-5.45(\mathrm{~m}, 3 \mathrm{H}), 5.30(\mathrm{t}, J=2.0 \mathrm{~Hz}, 1 \mathrm{H}), 4.96(\mathrm{~s}, 2 \mathrm{H}), 4.07(\mathrm{t}, J$ $=9.2 \mathrm{~Hz}, 1 \mathrm{H}), 3.04-2.78(\mathrm{~m}, 3 \mathrm{H}), 2.58-2.35(\mathrm{~m}, 2 \mathrm{H}), 2.34-2.15$ 
Table 2 (Contd.)

Entry Aryl iodide $\quad$ Product<smiles>CCc1ccccc1</smiles><smiles>O=[N+]([O-])c1ccccc1I</smiles>

10

11
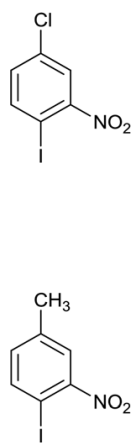
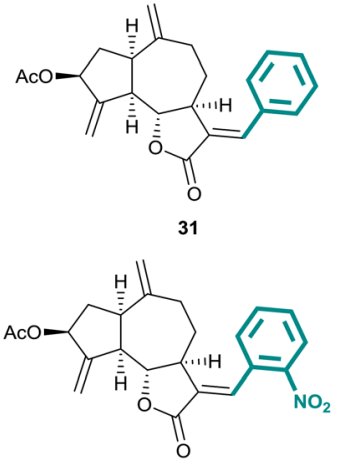

32

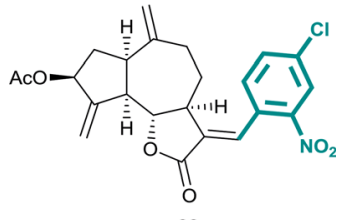

33

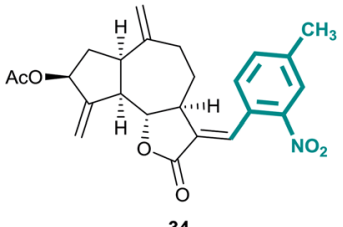

Table 3 In vitro anticancer activities of Michael adducts of zaluzanin D (3-22)

\begin{tabular}{llll}
\hline & IC in $\mu \mathrm{M}$ & & \\
\cline { 2 - 4 } Compound & MCF7 & MDA-MB-231 & MCF10A \\
\hline $\mathbf{1}$ (zaluzanin D) & $53.7 \pm 4.11$ & $34.17 \pm 4.48$ & $29.6 \pm 0.84$ \\
$\mathbf{2}$ (zaluzanin $\mathrm{C})$ & $>100$ & Not tested & Not tested \\
$\mathbf{3}$ & $71.2 \pm 0.9$ & Not tested & Not tested \\
$\mathbf{4}$ & $>100$ & Not tested & Not tested \\
$\mathbf{5}$ & $>100$ & Not tested & Not tested \\
$\mathbf{6}$ & $>100$ & Not tested & Not tested \\
$\mathbf{7}$ & $>100$ & Not tested & Not tested \\
$\mathbf{8}$ & $75.8 \pm 3$ & Not tested & Not tested \\
$\mathbf{9}$ & $30 \pm 0.7$ & $13.33 \pm 1.53$ & $42 \pm 4.1$ \\
$\mathbf{1 0}$ & $18.83 \pm 1.7$ & $23 \pm 1$ & $>100$ \\
$\mathbf{1 1}$ & $>100$ & Not tested & Not tested \\
$\mathbf{1 2}$ & $>100$ & Not tested & Not tested \\
$\mathbf{1 3}$ & $56.1 \pm 0.9$ & Not tested & Not tested \\
$\mathbf{1 4}$ & $40 \pm 2.16$ & $25 \pm 2.3$ & $>50$ \\
$\mathbf{1 5}$ & $>100$ & Not tested & Not tested \\
$\mathbf{1 6}$ & $>100$ & Not tested & Not tested \\
$\mathbf{1 7}$ & $>100$ & Not tested & Not tested \\
$\mathbf{1 8}$ & $>100$ & Not tested & Not tested \\
$\mathbf{1 9}$ & $>100$ & Not tested & Not tested \\
$\mathbf{2 0}$ & $>100$ & Not tested & Not tested \\
$\mathbf{2 1}$ & $>100$ & Not tested & Not tested \\
$\mathbf{2 2}$ & $>100$ & Not tested & Not tested
\end{tabular}

1H), $1.86-1.74(\mathrm{~m}, 2 \mathrm{H}), 1.36(\mathrm{~d}, J=6.9 \mathrm{~Hz}, 3 \mathrm{H}) ;{ }^{13} \mathrm{C} \mathrm{NMR}(100$ $\left.\mathrm{MHz}, \mathrm{CDCl}_{3}\right) \delta_{\mathrm{C}} 177.8,170.8,148.6,148.5,144.9,128.6,127.2$, 126.8, 113.6, 113.2, 84.3, 74.8, 58.4, 50.0, 47.3, 45.0, 44.5, 44.1, 36.4, 36.1, 32.1, 29.8, 24.5, 21.3; LCMS (ESI): $\mathrm{m} / z$ 432.05 (M + $\mathrm{Na})^{+}$; HRMS (ESI) calcd for $\mathrm{C}_{25} \mathrm{H}_{32} \mathrm{O}_{4} \mathrm{~N}[\mathrm{M}+\mathrm{H}]^{+} 410.2326$, found 410.2328 .

$(3 R, 3 a S, 6 a R, 8 S, 9 a R, 9 b S)-8-H y d r o x y-6,9-d i m e t h y l e n e-3-(((S)$ 1-phenylethyl)amino)methyl)decahydroazuleno $[4,5-b]$ furan2(3H)-one (4)

Dark brown viscous liquid (32\%); $R_{\mathrm{f}} 0.30$ (EtOAc-petroleum ether, $7: 3) ;[\alpha]_{\mathrm{D}}^{26}+21.1\left(c 1, \mathrm{CHCl}_{3}\right) ;{ }^{1} \mathrm{H} \mathrm{NMR}\left(400 \mathrm{MHz}, \mathrm{CDCl}_{3}\right)$ $\delta_{\mathrm{H}} 7.36-7.35(\mathrm{~m}, 2 \mathrm{H}), 7.34(\mathrm{~s}, 1 \mathrm{H}), 7.32-7.30(\mathrm{~m}, 2 \mathrm{H}), 5.36(\mathrm{t}, J=$ $1.8 \mathrm{~Hz}, 1 \mathrm{H}), 5.29(\mathrm{t}, J=2.3 \mathrm{~Hz}, 1 \mathrm{H}), 4.54(\mathrm{tt}, J=7.3,1.8 \mathrm{~Hz}, 1 \mathrm{H})$, $4.18(\mathrm{q}, J=6.8 \mathrm{~Hz}, 1 \mathrm{H}), 4.04(\mathrm{t}, J=9.6 \mathrm{~Hz}, 1 \mathrm{H}), 3.77(\mathrm{q}, J=$ $6.6 \mathrm{~Hz}, 1 \mathrm{H}), 2.93-2.75(\mathrm{~m}, 3 \mathrm{H}), 2.48-2.35(\mathrm{~m}, 3 \mathrm{H}), 2.34-2.27(\mathrm{~m}$, $1 \mathrm{H}), 2.26-2.16(\mathrm{~m}, 1 \mathrm{H}), 1.96-1.89(\mathrm{~m}, 1 \mathrm{H}), 1.89-1.85(\mathrm{~m}, 4 \mathrm{H})$, 1.84-1.77 (m, 1H), 1.78-1.68 (m, 1H), 1.36 (d, $J=6.4 \mathrm{~Hz}, 3 \mathrm{H})$; ${ }^{13} \mathrm{C} \mathrm{NMR}\left(100 \mathrm{MHz}, \mathrm{CDCl}_{3}\right) \delta_{\mathrm{C}} 177.9,153.4,148.8,144.9,128.8$, 128.6, 127.8, 126.8, 126.2, 113.6, 110.9, 84.4, 73.5, 58.4, 51.1, 47.2 , 45.4, 44.5, 43.7, 38.9, 35.9, 29.8, 24.5, 23.3; LCMS (ESI): $m / z$ $390.05(\mathrm{M}+\mathrm{Na})^{+}$; HRMS (ESI) calcd for $\mathrm{C}_{23} \mathrm{H}_{30} \mathrm{O}_{3} \mathrm{~N}[\mathrm{M}+\mathrm{H}]^{+}$ 368.2220 , found 368.2220 .

$(3 R, 3 a S, 6 a R, 8 S, 9 a R, 9 b S)-6,9-D i m e t h y l e n e-2-o x o-3-((((R)-1-$ phenyl ethyl)amino)methyl)dodecahydroazuleno[4,5-b]furan8-yl-acetate (5)

Brown viscous liquid (66\%); $R_{\mathrm{f}} 0.30$ (EtOAc-petroleum ether, $2: 3) ;[\alpha]_{\mathrm{D}}^{26}+34.4\left(c 1, \mathrm{CHCl}_{3}\right) ;{ }^{1} \mathrm{H} \mathrm{NMR}\left(200 \mathrm{MHz}, \mathrm{CDCl}_{3}\right) \delta_{\mathrm{H}}$ $7.37-7.22(\mathrm{~m}, 5 \mathrm{H}), 5.59-548(\mathrm{~m}, 1 \mathrm{H}), 5.40(\mathrm{t}, J=2.0 \mathrm{~Hz}, 1 \mathrm{H}), 5.26$ $(\mathrm{t}, J=2.0 \mathrm{~Hz}, 1 \mathrm{H}), 4.90(\mathrm{~s}, 2 \mathrm{H}), 4.00(\mathrm{t}, J=9.2 \mathrm{~Hz}, 1 \mathrm{H}), 3.75(\mathrm{q}, J$ $=6.6 \mathrm{~Hz}, 1 \mathrm{H}), 2.96-2.75(\mathrm{~m}, 2 \mathrm{H}), 2.70(\mathrm{~s}, 1 \mathrm{H}), 2.67(\mathrm{~s}, 1 \mathrm{H}), 2.55-$ $2.28(\mathrm{~m}, 3 \mathrm{H}), 2.26-2.14(\mathrm{~m}, 1 \mathrm{H}), 2.10(\mathrm{~s}, 3 \mathrm{H}), 2.05-1.96(\mathrm{~m}, 3 \mathrm{H})$, $1.79(\mathrm{td}, J=14.2,6.4 \mathrm{~Hz}, 1 \mathrm{H}), 1.56(\mathrm{~d}, J=6.3 \mathrm{~Hz}, 1 \mathrm{H}), 1.35(\mathrm{~d}, J=$ $6.6 \mathrm{~Hz}, 3 \mathrm{H}) ;{ }^{13} \mathrm{C} \mathrm{NMR}\left(125 \mathrm{MHz}, \mathrm{CDCl}_{3}\right) \delta_{\mathrm{C}} 177.6,170.8,148.5$, 148.3, 144.3, 128.6, 127.2, 126.7, 113.6, 113.2, 84.2, 74.7, 58.7, 49.9, 47.2, 45.9, 45.7, 44.0, 36.3, 36.1, 32.4, 29.7, 23.9, 21.3; LCMS (ESI): $m / z 432.05(\mathrm{M}+\mathrm{Na})^{+}$; HRMS (ESI) calcd for $\mathrm{C}_{25} \mathrm{H}_{32} \mathrm{O}_{4} \mathrm{~N}[\mathrm{M}+\mathrm{H}]^{+}$410.2326, found 410.2329.

$(3 R, 3 a S, 6 a R, 8 S, 9 a R, 9 b S)-8-H y d r o x y-6,9-d i m e t h y l e n e-3-((((R)-$ 1-phenylethyl)amino)methyl)decahydroazuleno[4,5- $b]$ furan2(3H)-one (6)

Brown viscous liquid (28\%); $R_{\mathrm{f}} 0.30$ (EtOAc-petroleum ether, $7: 3) ;[\alpha]_{\mathrm{D}}^{26}+33.1\left(c 1, \mathrm{CHCl}_{3}\right) ;{ }^{1} \mathrm{H} \mathrm{NMR}\left(200 \mathrm{MHz}, \mathrm{CDCl}_{3}\right) \delta_{\mathrm{H}}$ $7.36-7.26(\mathrm{~m}, 5 \mathrm{H}), 5.37(\mathrm{t}, J=1.9 \mathrm{~Hz}, 1 \mathrm{H}), 5.29(\mathrm{t}, J=1.8 \mathrm{~Hz}, 1 \mathrm{H})$, $4.96(\mathrm{~s}, 1 \mathrm{H}), 4.91(\mathrm{~s}, 1 \mathrm{H}), 4.59-4.48(\mathrm{~m}, 1 \mathrm{H}), 4.03(\mathrm{t}, J=9.4 \mathrm{~Hz}$, $1 \mathrm{H}), 3.75(\mathrm{q}, J=6.6 \mathrm{~Hz}, 1 \mathrm{H}), 2.93-2.75(\mathrm{~m}, 2 \mathrm{H}), 2.69(\mathrm{~s}, 1 \mathrm{H}), 2.66$ (s, 1H), 2.51-2.27 (m, 3H), 2.00-1.96 (m, 6H), 1.80-1.66 (m, 1H), 1.62-1.47 (m, 1H), 1.35 (d, $J=6.7 \mathrm{~Hz}, 3 \mathrm{H}) ;{ }^{13} \mathrm{C}$ NMR $(125 \mathrm{MHz}$, $\left.\mathrm{CDCl}_{3}\right) \delta_{\mathrm{C}} 177.8,153.3,148.7,144.6,128.6,127.2$, 126.7, 113.7, 110.9, 84.3, 73.5, 58.7, 49.6, 47.3, 46.3, 45.8, 43.6, 38.8, 35.9, 32.4, 29.7, 24.0; LCMS (ESI): $m / z 390.07$ (M + Na) ${ }^{+}$; HRMS (ESI) calcd for $\mathrm{C}_{23} \mathrm{H}_{30} \mathrm{O}_{3} \mathrm{~N}[\mathrm{M}+\mathrm{H}]^{+}$368.2220, found 368.2208. 


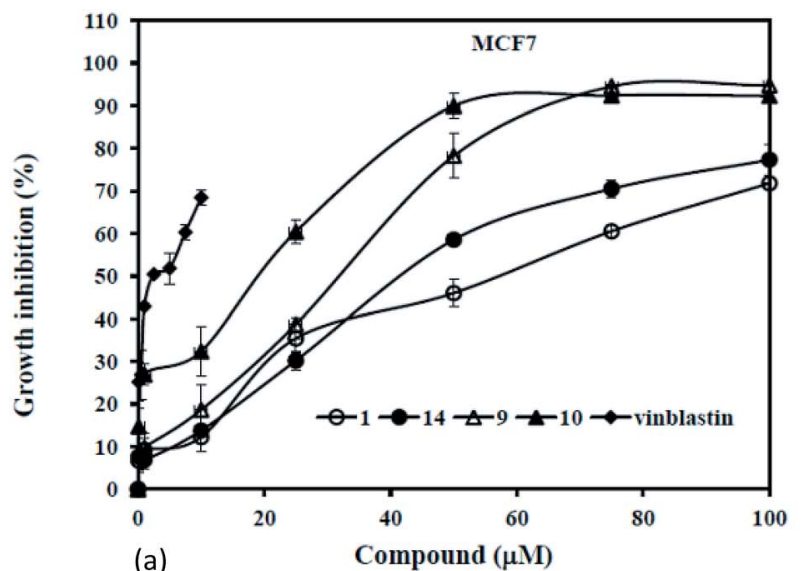

(a)
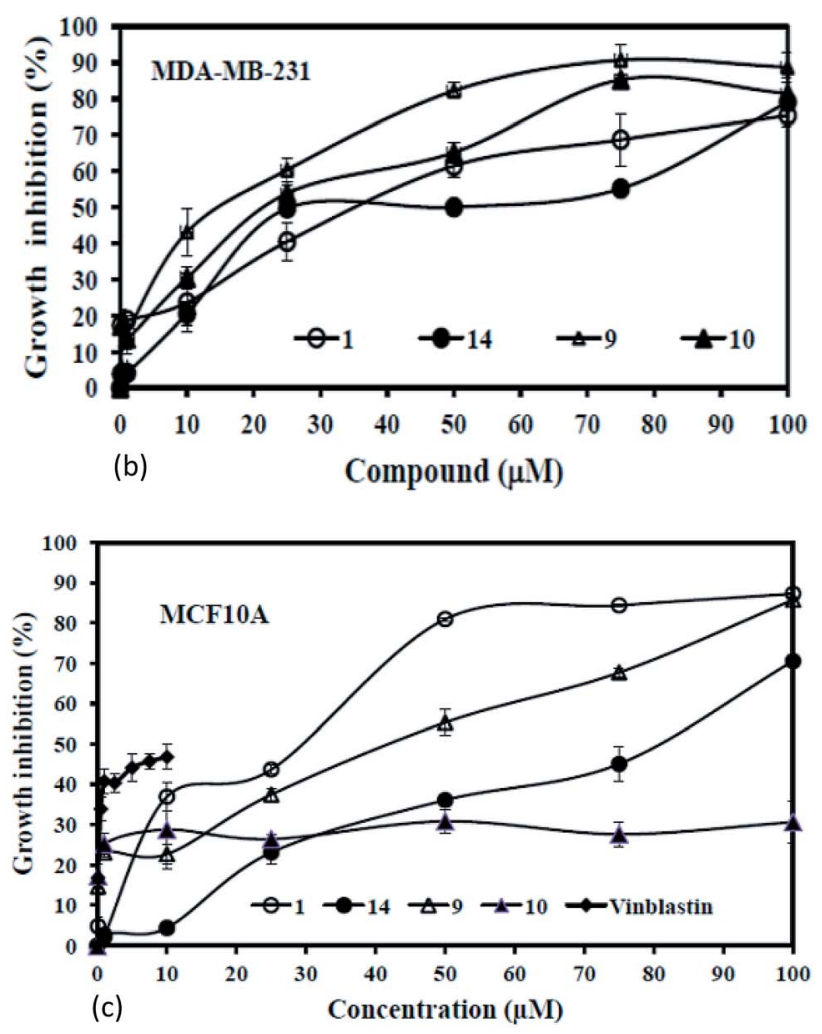

Fig. 5 Effect of selected compounds on growth of breast cancer and normal cell lines. Breast cancer cell line (a) MCF7 (b) MDA-MB-231 and (c) MCF10A were exposed to different concentrations of compounds for $48 \mathrm{~h}$, and then MTT assay was performed as described in experimental section. MTT assay was repeated three times and mean values were plotted with standard deviation.

$(3 R, 3 a S, 6 a R, 8 S, 9 a R, 9 b S)-6,9-D i m e t h y l e n e-3-((((S)-1-$ (naphthalen-1-yl)ethyl)amino)methyl)-2oxododecahydroazuleno[ $[4,5-b]$ furan-8-yl acetate (7)

Dark brown viscous liquid (52\%); $R_{\mathrm{f}} 0.60$ (EtOAc-petroleum ether, $1: 1) ;[\alpha]_{\mathrm{D}}^{25}+20.4\left(c 1, \mathrm{CHCl}_{3}\right) ;{ }^{1} \mathrm{H}$ NMR (200 $\left.\mathrm{MHz}, \mathrm{CDCl}_{3}\right)$ $\delta_{\mathrm{H}} 8.29(\mathrm{~d}, J=7.6 \mathrm{~Hz}, 1 \mathrm{H}), 7.94-7.83(\mathrm{~m}, 1 \mathrm{H}), 7.76(\mathrm{~d}, J=8.0 \mathrm{~Hz}$, $1 \mathrm{H}), 7.62(\mathrm{~d}, J=7.0 \mathrm{~Hz}, 1 \mathrm{H}), 7.55-7.42(\mathrm{~m}, 3 \mathrm{H}), 5.54(\mathrm{t}, J=$ $7.0 \mathrm{~Hz}, 1 \mathrm{H}), 5.40(\mathrm{~s}, 1 \mathrm{H}), 5.26(\mathrm{~s}, 1 \mathrm{H}), 4.86(\mathrm{~s}, 2 \mathrm{H}), 4.72-4.52(\mathrm{~m}$, $1 \mathrm{H}), 3.98(\mathrm{t}, J=8.2 \mathrm{~Hz}, 1 \mathrm{H}), 3.03(\mathrm{~d}, J=11.2 \mathrm{~Hz}, 2 \mathrm{H}), 2.84-2.72$ (m, 2H), 2.60-2.33 (m, 4H), $2.10(\mathrm{~s}, 3 \mathrm{H}), 1.85-1.66(\mathrm{~m}, 3 \mathrm{H}), 1.53$ $(\mathrm{d}, J=6.4 \mathrm{~Hz}, 3 \mathrm{H}), 1.18-1.04(\mathrm{~m}, 2 \mathrm{H}) ;{ }^{13} \mathrm{C} \mathrm{NMR}(100 \mathrm{MHz}$, $\left.\mathrm{CDCl}_{3}\right) \delta_{\mathrm{C}} 177.8,170.9,148.8,148.5,143.2$, 140.5, 134.0, 130.8, 129.1, 127.4, 126.1, 125.7, 125.5, 123.0, 121.5, 113.4, 113.0, 84.3, 74.8, 53.9, 49.9, 48.0, 46.6, 45.5, 45.0, 43.9, 36.4, 32.5, 24.8, 23.3, 21.4; LCMS (ESI): $m / z 482.09(\mathrm{M}+\mathrm{Na})^{+}$; HRMS (ESI) calcd for $\mathrm{C}_{29} \mathrm{H}_{34} \mathrm{O}_{4} \mathrm{~N}[\mathrm{M}+\mathrm{H}]^{+}$460.2482, found 460.2487.

$(3 R, 3 a S, 6 a R, 8 S, 9 a R, 9 b S)-8-H y d r o x y-6,9-d i m e t h y l e n e-3-((((S)-$ 1-(naphthalene-1-yl)ethyl)amino)methyl)decahydroazuleno $[4,5-b]$ furan-2 $(3 H)$-one $(8)$

Dark brown viscous liquid (27\%); $R_{\mathrm{f}} 0.30$ (EtOAc-petroleum ether, $1: 1) ;[\alpha]_{\mathrm{D}}^{25}+35.1$ ( c 1, $\left.\mathrm{CHCl}_{3}\right) ;{ }^{1} \mathrm{H} \mathrm{NMR}\left(400 \mathrm{MHz}, \mathrm{CDCl}_{3}\right.$ ) $\delta_{\mathrm{H}} 8.22(\mathrm{~d}, J=8.2 \mathrm{~Hz}, 1 \mathrm{H}), 7.90-7.84(\mathrm{~m}, 1 \mathrm{H}), 7.75(\mathrm{~d}, J=8.2 \mathrm{~Hz}$, $1 \mathrm{H}), 7.64(\mathrm{~d}, J=6.9 \mathrm{~Hz}, 1 \mathrm{H}), 7.54-7.45(\mathrm{~m}, 3 \mathrm{H}), 5.35(\mathrm{~s}, 1 \mathrm{H}), 5.28$ $(\mathrm{s}, 1 \mathrm{H}), 4.92(\mathrm{~s}, 1 \mathrm{H}), 4.86(\mathrm{~s}, 1 \mathrm{H}), 4.65(\mathrm{q}, J=6.4 \mathrm{~Hz}, 1 \mathrm{H}), 4.52(\mathrm{t}, J$ $=7.8 \mathrm{~Hz}, 1 \mathrm{H}), 4.05-3.95(\mathrm{~m}, 1 \mathrm{H}), 2.85(\mathrm{dd}, J=12.4,4.1, \mathrm{~Hz}, 1 \mathrm{H})$, 2.77-2.65 (m, 3H), 2.43-2.22 (m, 4H), 2.21-2.13 (m, 1H), 2.11$2.01(\mathrm{~m}, 1 \mathrm{H}), 1.91-1.82(\mathrm{~m}, 1 \mathrm{H}), 1.83-1.65(\mathrm{~m}, 3 \mathrm{H}), 1.52(\mathrm{~d}, J=$ $6.4 \mathrm{~Hz}, 3 \mathrm{H}) ;{ }^{13} \mathrm{C} \mathrm{NMR}\left(100 \mathrm{MHz}, \mathrm{CDCl}_{3}\right) \delta_{\mathrm{C}} 177.9,153.4,148.9$, 140.4 , 134.1, 131.5, 129.0, 127.4, 125.8, 125.7, 125.4, 123.4, 123.0, 113.5, 110.8, 84.3, 73.6, 53.9, 49.6, 47.9, 46.0, 45.2, 43.5, 38.8, 36.1, 32.5, 23.3; LCMS (ESI): $m / z$ 440.14 (M + Na) ${ }^{+}$; HRMS (ESI) calcd for $\mathrm{C}_{27} \mathrm{H}_{32} \mathrm{O}_{3} \mathrm{~N}[\mathrm{M}+\mathrm{H}]^{+}$418.2377, found 418.2373.

$(3 R, 3 a S, 6 a R, 8 S, 9 a R, 9 b S)-6,9-D i m e t h y l e n e-3-((((R)-1-$ (naphthalen-1-yl)ethyl)amino)methyl)-2oxododecahydroazuleno $[4,5-b]$ furan-8-yl acetate (9)

Pale yellow viscous liquid (57\%); $R_{\mathrm{f}} 0.70$ (EtOAc-petroleum ether, $7: 3) ;[\alpha]_{\mathrm{D}}^{25}+30.9\left(c 1, \mathrm{CHCl}_{3}\right) ;{ }^{1} \mathrm{H}$ NMR (500 MHz, $\left.\mathrm{CDCl}_{3}\right)$ $\delta_{\mathrm{H}} 8.29(\mathrm{~d}, J=7.9 \mathrm{~Hz}, 1 \mathrm{H}), 7.87(\mathrm{~d}, J=7.6 \mathrm{~Hz}, 1 \mathrm{H}), 7.75(\mathrm{~d}, J=$ $7.9 \mathrm{~Hz}, 1 \mathrm{H}), 7.61(\mathrm{~d}, J=7.0 \mathrm{~Hz}, 1 \mathrm{H}), 7.55-7.40(\mathrm{~m}, 3 \mathrm{H}), 5.54(\mathrm{t}, J$ $=7.0 \mathrm{~Hz}, 1 \mathrm{H}), 5.40(\mathrm{~s}, 1 \mathrm{H}), 5.27(\mathrm{~s}, 1 \mathrm{H}), 4.88-4.85(\mathrm{~m}, 2 \mathrm{H}), 4.60$ (q, $J=6.3 \mathrm{~Hz}, 1 \mathrm{H}), 3.98(\mathrm{t}, J=8.7 \mathrm{~Hz}, 1 \mathrm{H}), 3.02(\mathrm{dd}, J=12.2$, $2.8 \mathrm{~Hz}, 1 \mathrm{H}), 2.87-2.69(\mathrm{~m}, 2 \mathrm{H}), 2.52(\mathrm{dd}, J=12.2,5.5 \mathrm{~Hz}, 1 \mathrm{H})$, 2.48-2.40 (m, 1H), 2.40-2.25 (m, 3H), 2.10 (s, 3H), 1.84-1.62 (m, $3 \mathrm{H}), 1.52$ (d, $J=6.7 \mathrm{~Hz}, 3 \mathrm{H}), 1.19-1.07$ (m, 2H); ${ }^{13} \mathrm{C}$ NMR (125 $\left.\mathrm{MHz}, \mathrm{CDCl}_{3}\right) \delta_{\mathrm{C}} 177.7,170.8,148.6,148.4,143.1,140.3,133.9$, 130.7 , 129.0, 127.2, 126.0, 125.6, 125.4, 122.9, 121.4, 113.3, 112.9, 84.1, 74.7, 53.8, 49.8, 47.9, 46.4, 45.4, 44.9, 43.8, 36.3, 32.3, 24.7, 23.1, 21.2; LCMS (ESI): $m / z 482.05$ (M + Na) ${ }^{+}$; HRMS (ESI) calcd for $\mathrm{C}_{29} \mathrm{H}_{34} \mathrm{O}_{4} \mathrm{~N}[\mathrm{M}+\mathrm{H}]^{+} 460.2482$, found 460.2487 .

$(3 R, 3 a S, 6 a R, 8 S, 9 a R, 9 b S)-8-H y d r o x y-6,9-d i m e t h y l e n e-3-((((R))$ 1-(naphthalen-1-yl)ethyl)amino)methyl)decahydroazuleno $[4,5-b]$ furan-2(3H)-one (10)

Pale yellow viscous liquid (34\%); $R_{\mathrm{f}} 0.40$ (EtOAc-petroleum ether, $7: 3) ;[\alpha]_{\mathrm{D}}^{25}+24.6\left(c 1, \mathrm{CHCl}_{3}\right) ;{ }^{1} \mathrm{H} \mathrm{NMR}\left(400 \mathrm{MHz}, \mathrm{CDCl}_{3}\right)$ $\delta_{\mathrm{H}} 8.24(\mathrm{~d}, J=8.2 \mathrm{~Hz}, 1 \mathrm{H}), 7.89-7.85(\mathrm{~m}, 1 \mathrm{H}), 7.75(\mathrm{~d}, J=8.2 \mathrm{~Hz}$, $1 \mathrm{H}), 7.64(\mathrm{~d}, J=6.9 \mathrm{~Hz}, 1 \mathrm{H}), 7.53-7.46(\mathrm{~m}, 3 \mathrm{H}), 5.35(\mathrm{~s}, 1 \mathrm{H}), 5.28$ $(\mathrm{s}, 1 \mathrm{H}), 4.92(\mathrm{~s}, 1 \mathrm{H}), 4.86(\mathrm{~s}, 1 \mathrm{H}), 4.66(\mathrm{q}, J=6.4 \mathrm{~Hz}, 1 \mathrm{H}), 4.53(\mathrm{t}, J$ $=7.8 \mathrm{~Hz}, 1 \mathrm{H}), 4.04-3.97(\mathrm{~m}, 1 \mathrm{H}), 2.87(\mathrm{dd}, J=12.4,4.1 \mathrm{~Hz}, 1 \mathrm{H})$, 2.76-2.67 (m, 3H), 2.43-2.26 (m, 4H), 2.20-2.14 (m, 1H), 2.06 (dq, $J=11.9,3.7 \mathrm{~Hz}, 1 \mathrm{H}), 1.90-1.82(\mathrm{~m}, 1 \mathrm{H}), 1.83-1.66(\mathrm{~m}, 3 \mathrm{H})$, $1.53(\mathrm{~d}, J=6.4 \mathrm{~Hz}, 3 \mathrm{H}), 1.30-1.16(\mathrm{~m}, 2 \mathrm{H}) ;{ }^{13} \mathrm{C}$ NMR $(100 \mathrm{MHz}$, $\left.\mathrm{CDCl}_{3}\right) \delta_{\mathrm{C}} 177.8,153.3,148.7,140.3,134.0,131.4,128.9,127.3$, 

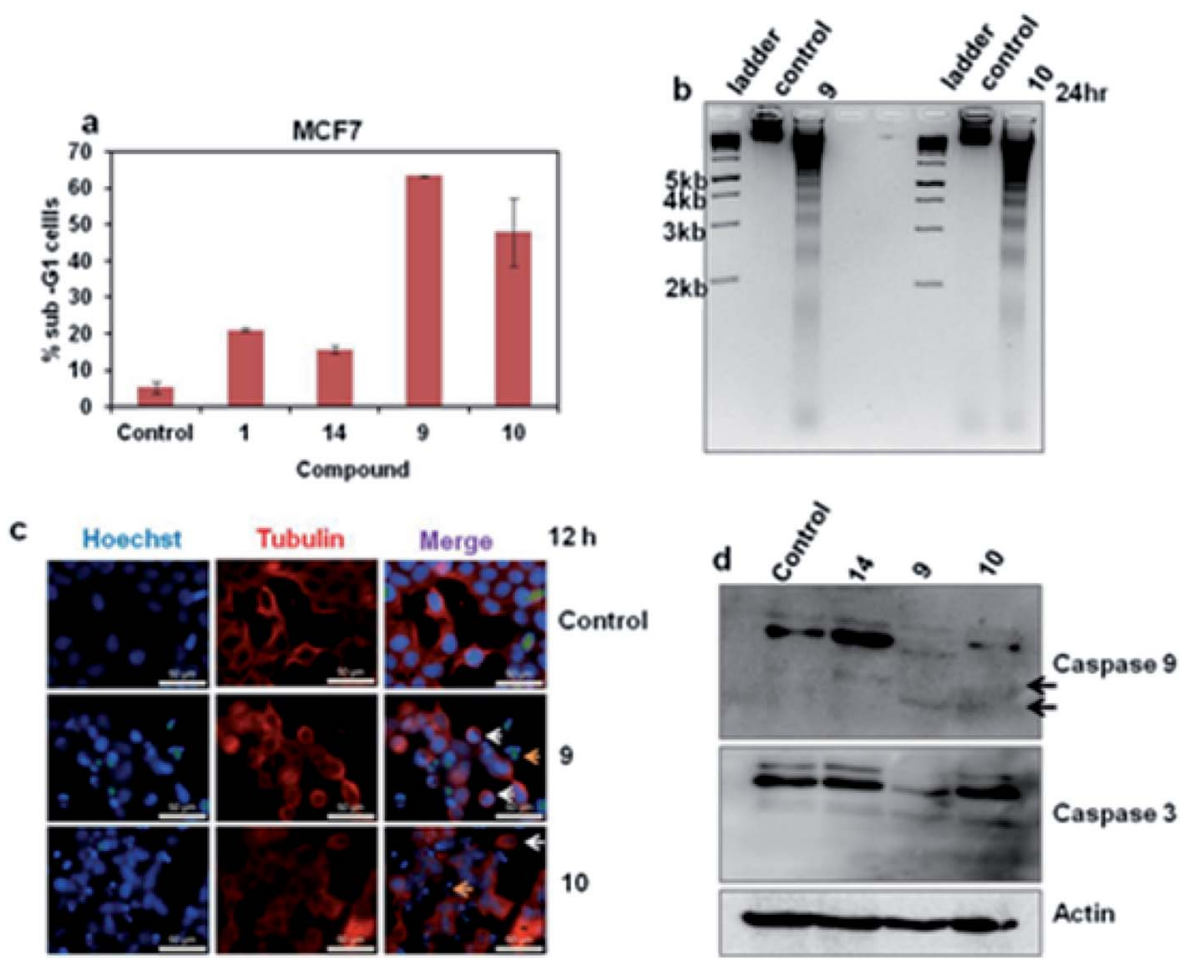

Fig. 6 Compounds 9 and 10 promote apoptosis in cancer cell line. (a) MCF7 cells were grown in the presence of $30 \mu \mathrm{M}$ of 9 , and $20 \mu \mathrm{M}$ of 10 for $24 \mathrm{~h}$ and cells were then collected for FACS analysis as mentioned in material and methods. The experiment was repeated three times and mean of the sub-G1 population was plotted. (b) Compounds 9 and 10 promoted DNA fragmentation of MCF7 cells. MCF7 cells were exposed to either vehicle (DMSO) or $30 \mu \mathrm{M}$ of 9 or $20 \mu \mathrm{M}$ of 10 for $24 \mathrm{~h}$. Cells were then collected, and fragmented DNA was isolated as described in the experimental section. (c) Immunofluorescence data depicts the fragmentation of genomic DNA following treatment of compound 9 and 10 clearly show fragmented DNA (white arrows) and stressed tubulin morphology (orange arrows). Red: tubulin, blur: Hoechst. (d) Compound 9 and 10 induce apoptosis through intrinsic pathway. MCF7 cells were exposed with either vehicle (DMSO) or $30 \mu \mathrm{M}$ of 9 or $20 \mu \mathrm{M}$ of 10 for 24 h. Cells were then collected, lysed, and whole cell protein extracts were immunoblotted for indicated proteins.

Table 4 In vitro anticancer activities of Heck analogs of zaluzanin D (23-34)

\begin{tabular}{lc}
\hline & \multicolumn{2}{l}{$\begin{array}{l}\mathrm{IC}_{50} \text { in } \\
\mu \mathrm{M}\end{array}$} \\
\cline { 2 - 2 } Compound & $\mathrm{MCF} 7$ \\
\hline 23 & $>100$ \\
$\mathbf{2 4}$ & $>100$ \\
25 & $>100$ \\
$\mathbf{2 6}$ & $>100$ \\
27 & $>100$ \\
28 & $>100$ \\
29 & 74 \\
30 & $>100$ \\
31 & 37 \\
$\mathbf{3 2}$ & 36.5 \\
33 & $>100$ \\
34 & $>100$
\end{tabular}

125.7, 125.6, 125.3, 123.2, 122.9, 113.4, 110.6, 84.2, 76.7, 73.5, 53.8, 49.5, 47.8, 45.9, 45.0, 43.4, 38.7, 36.0, 32.3, 23.2; LCMS (ESI): $m / z 440.02(\mathrm{M}+\mathrm{Na})^{+}$; HRMS (ESI) calcd for $\mathrm{C}_{27} \mathrm{H}_{32} \mathrm{O}_{3} \mathrm{~N}[\mathrm{M}$ $+\mathrm{H}]^{+}$418.2377, found 418.2379.
(3R,3aS,6aR,8S,9aR,9bS)-3-((((R)-1-Cyclohexylethyl)amino) methyl)-8-hydroxy-6,9-dimethylenedecahydroazuleno[ $[4,5-b]$ furan-2(3H)-one (11)

Brown viscous liquid (88\%); $R_{\mathrm{f}} 0.40$ (EtOAc); $[\alpha]_{\mathrm{D}}^{24}+17.5$ (c 1 , $\left.\mathrm{CHCl}_{3}\right) ;{ }^{1} \mathrm{H} \mathrm{NMR}\left(400 \mathrm{MHz}, \mathrm{CDCl}_{3}\right) \delta_{\mathrm{H}} 5.34(\mathrm{~s}, 1 \mathrm{H}), 5.31(\mathrm{~s}, 1 \mathrm{H})$, 4.99-4.89 (m, 2H), $4.54(\mathrm{t}, J=7.3 \mathrm{~Hz}, 1 \mathrm{H}), 4.23-4.08(\mathrm{~m}, 1 \mathrm{H})$, $3.42(\mathrm{dd}, J=11.2,3.4 \mathrm{~Hz}, 1 \mathrm{H}), 2.97-2.73(\mathrm{~m}, 4 \mathrm{H}), 2.55-2.45(\mathrm{~m}$, $1 \mathrm{H}), 2.36-2.27(\mathrm{~m}, 1 \mathrm{H}), 2.23-2.07(\mathrm{~m}, 2 \mathrm{H}), 2.04-2.01(\mathrm{~m}, 5 \mathrm{H})$, 1.84-1.65 (m, 6H), 1.65-1.51 (m, 2H), 1.49-1.34 (m, 2H), 1.20 (d, $J=6.9 \mathrm{~Hz}, 3 \mathrm{H}), 1.10-1.01(\mathrm{~m}, 2 \mathrm{H}) ;{ }^{13} \mathrm{C} \mathrm{NMR}\left(100 \mathrm{MHz}, \mathrm{CDCl}_{3}\right)$ $\delta_{\mathrm{C}} 178.3,176.1,153.0,148.2,114.0,111.1,85.1,73.4,59.7,49.4$, 46.5, 45.0, 44.5, 43.6, 40.5, 38.7, 35.3, 31.5, 29.7, 29.5, 29.3, 27.2, 26.2, 26.1, 25.9, 21.7, 14.0; LCMS (ESI): $m / z 396.15(\mathrm{M}+\mathrm{Na})^{+}$; HRMS (ESI) calcd for $\mathrm{C}_{23} \mathrm{H}_{36} \mathrm{O}_{3} \mathrm{~N}[\mathrm{M}+\mathrm{H}]^{+} 374.2690$, found 374.2685 .

$(3 R, 3 a S, 6 a R, 8 S, 9 a R, 9 b S)-3-((((S)-1-C y c l o h e x y l e t h y l) a m i n o)$ methyl)-8-hydroxy-6,9-dimethylenedecahydroazuleno[ $[4,5-b]$ furan-2(3H)-one (12)

Dark brown viscous liquid (86\%); $R_{\mathrm{f}} 0.30$ (EtOAc-petroleum ether, $7: 3) ;[\alpha]_{\mathrm{D}}^{26}+25.9\left(c 1, \mathrm{CHCl}_{3}\right) ;{ }^{1} \mathrm{H} \mathrm{NMR}\left(500 \mathrm{MHz}, \mathrm{CDCl}_{3}\right)$ $\delta_{\mathrm{H}} 5.38-5.26(\mathrm{~m}, 2 \mathrm{H}), 4.9-4.91(\mathrm{~m}, 2 \mathrm{H}), 4.55(\mathrm{t}, J=7.6 \mathrm{~Hz}, 1 \mathrm{H})$, $4.15(\mathrm{t}, J=9.5 \mathrm{~Hz}, 1 \mathrm{H}), 3.19-3.15(\mathrm{~m}, 1 \mathrm{H}), 2.97-2.74(\mathrm{~m}, 4 \mathrm{H})$, 
2.54-2.47 (m, 1H), 2.38-2.28 (m, 1H), 2.23-2.10 (m, 2H), 2.051.96 (m, 5H), 1.80-1.65 (m, 6H), 1.59-1.52 (m, 1H), 1.47-1.36 (m, 2H), 1.30-1.27 (m, 1H), 1.14 (d, $J=6.5 \mathrm{~Hz}, 3 \mathrm{H}), 1.09-1.00$ $(\mathrm{m}, 2 \mathrm{H}) ;{ }^{13} \mathrm{C}$ NMR $\left(125 \mathrm{MHz}, \mathrm{CDCl}_{3}\right) \delta_{\mathrm{C}} 177.8,176.0,153.1$, 148.4, 113.9, 111.0, 84.9, 77.3, 77.0, 76.8, 73.5, 58.0, 49.4, 46.3, 45.0, 43.6, 43.3, 40.9, 38.7, 35.6, 31.9, 29.7, 27.3, 26.3, 26.2, 26.0, 21.7, 14.3; LCMS (ESI): $m / z 396.13(\mathrm{M}+\mathrm{Na})^{+}$; HRMS (ESI) calcd for $\mathrm{C}_{23} \mathrm{H}_{36} \mathrm{O}_{3} \mathrm{~N}[\mathrm{M}+\mathrm{H}]^{+}$374.2690, found 374.2693.

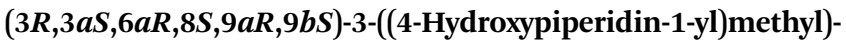
6,9-dimethylene-2-oxododecahydroazuleno[4,5-b]furan-8-ylacetate (13)

Pale yellow viscous liquid (73\%); $R_{\mathrm{f}} 0.50$ (MeOH-DCM, $\left.1: 9\right)$; $[\alpha]_{\mathrm{D}}^{25}+63.2\left(c 1, \mathrm{CHCl}_{3}\right) ;{ }^{1} \mathrm{H}$ NMR $\left(400 \mathrm{MHz}, \mathrm{CDCl}_{3}\right) \delta_{\mathrm{H}} 5.54(\mathrm{t}, J=$ $7.3 \mathrm{~Hz}, 1 \mathrm{H}), 5.40(\mathrm{~m}, 1 \mathrm{H}), 5.27(\mathrm{~m}, 1 \mathrm{H}), 4.93-4.89(\mathrm{~m}, 2 \mathrm{H}), 4.01$ $(\mathrm{t}, J=9.4 \mathrm{~Hz}, 1 \mathrm{H}), 3.74-3.65(\mathrm{~m}, 1 \mathrm{H}), 2.93(\mathrm{q}, J=7.9 \mathrm{~Hz}, 1 \mathrm{H})$, 2.84-2.74 (m, 3H), 2.74-2.66 (m, 1H), 2.64-2.56 (m, 1H), 2.52$2.31(\mathrm{~m}, 4 \mathrm{H}), 2.31-2.15(\mathrm{~m}, 3 \mathrm{H}), 2.11(\mathrm{~s}, 3 \mathrm{H}), 2.09-2.02(\mathrm{~m}, 1 \mathrm{H})$, 1.93-1.76 (m, 4H), 1.64-1.48 (m, 2H), 1.42-1.32 (m, $1 \mathrm{H}) ;{ }^{13} \mathrm{C}$ NMR $\left(100 \mathrm{MHz}, \mathrm{CDCl}_{3}\right) \delta_{\mathrm{C}} 177.5,170.9,148.8,148.4,113.5$, $113.3,83.9,74.8,67.9,57.6,52.2,50.9,50.2,47.9,45.3,44.2$, 36.4, 36.3, 34.6, 34.3, 32.8, 21.4; LCMS (ESI): $m / z 412.07$ (M + $\mathrm{Na})^{+}$; HRMS (ESI) calcd for $\mathrm{C}_{22} \mathrm{H}_{32} \mathrm{O}_{5} \mathrm{~N}[\mathrm{M}+\mathrm{H}]^{+} 390.2275$, found 390.2272 .

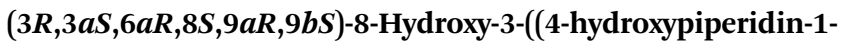
yl) methyl)-6,9-di-methylenedecahydroazuleno[4,5-b]furan2(3H)-one (14)

Pale yellow viscous liquid (20\%); $R_{\mathrm{f}} 0.40$ (MeOH-DCM, $\left.1: 9\right)$; $[\alpha]_{\mathrm{D}}^{25}+61.8\left(c 1, \mathrm{CHCl}_{3}\right) ;{ }^{1} \mathrm{H}$ NMR $\left(400 \mathrm{MHz}, \mathrm{CD}_{3} \mathrm{OD}\right) \delta_{\mathrm{H}} 5.28-5.23$ $(\mathrm{m}, 2 \mathrm{H}), 5.01-4.88(\mathrm{~m}, 1 \mathrm{H}), 4.56-4.45(\mathrm{~m}, 1 \mathrm{H}), 4.17-4.06(\mathrm{~m}$, $1 \mathrm{H}), 3.66-3.53(\mathrm{~m}, 1 \mathrm{H}), 3.20-3.10(\mathrm{~m}, 1 \mathrm{H}), 3.00-2.88(\mathrm{~m}, 2 \mathrm{H})$, 2.86-2.79 (m, 2H), 2.77-2.70 (m, 2H), 2.63-2.53 (m, 2H), 2.52$2.46(\mathrm{~m}, 1 \mathrm{H}), 2.31-2.20(\mathrm{~m}, 4 \mathrm{H}), 2.17-2.03(\mathrm{~m}, 2 \mathrm{H}), 1.96-1.78$ (m, 3H), 1.73-1.66 (m, 1H), 1.58-1.49 (m, 2H), 1.45-1.37 (m, $1 \mathrm{H}) ;{ }^{13} \mathrm{C}$ NMR $\left(100 \mathrm{MHz}, \mathrm{CDCl}_{3}\right) \delta \delta_{\mathrm{C}} 178.7,153.3,149.4,112.0$, 108.2, 84.2, 72.4, 66.9, 56.9, 51.8, 50.8, 48.9, 44.8, 42.9, 38.0, 35.5, 33.6, 33.5, 32.2; LCMS (ESI): $m / z 370.12(\mathrm{M}+\mathrm{Na})^{+}$; HRMS (ESI) calcd for $\mathrm{C}_{20} \mathrm{H}_{30} \mathrm{O}_{4} \mathrm{~N}[\mathrm{M}+\mathrm{H}]^{+} 348.2169$, found 348.2156.

\section{$\left(3 R, 3 a S, 3^{\prime} R, 3 a^{\prime} S, 6 a R, 6 a^{\prime} R, 8 S, 8^{\prime} S, 9 a R, 9 b S, 9 a^{\prime} R, 9 b^{\prime} S\right)-$}

(Piperazine-1,4 diylbis(methylene))bis(6,9-dimethylene-2oxododecahydro azuleno[4,5-b]furan-3,8-diyl)diacetate (15)

Pale yellow viscous liquid (26\%); $R_{\mathrm{f}} 0.40$ (EtOAc-petroleum ether, $7: 3) ;[\alpha]_{\mathrm{D}}^{26}+67.7\left(c 1, \mathrm{CHCl}_{3}\right) ;{ }^{1} \mathrm{H} \mathrm{NMR}\left(200 \mathrm{MHz}, \mathrm{CDCl}_{3}\right)$ $\delta_{\mathrm{H}}$ 5.61-5.49 (m, 2H), 5.72-5.39 (m, 2H), 5.29-5.26 (m, 2H), 4.95-4.90 (m, 4H), $4.01(\mathrm{t}, J=9.5 \mathrm{~Hz}, 2 \mathrm{H}), 2.96-2.74(\mathrm{~m}, 6 \mathrm{H})$, 2.67-2.58 (m, 2H), 2.56-2.38 (m, 14H), 2.33-2.27 (m, 2H), 2.26$2.16(\mathrm{~m}, 2 \mathrm{H}), 2.11$ (s, 6H), 2.04-1.96 (m, 2H), 1.88-1.74 (m, 2H), 1.46-1.38 (m, 2H); ${ }^{13} \mathrm{C}$ NMR (100 MHz, $\left.\mathrm{CDCl}_{3}\right) \delta_{\mathrm{C}} 177.4,170.9$, 148.8, 148.4 113.5, 113.4, 83.9, 74.8, 57.6, 57.6, 53.5, 53.5, 50.1, 47.9, 47.9, 45.2, 44.2, 36.4, 36.3, 32.8, 21.4; LCMS (ESI): $m / z$ $685.39(\mathrm{M}+\mathrm{Na})^{+}$; HRMS (ESI) calcd for $\mathrm{C}_{38} \mathrm{H}_{51} \mathrm{O}_{8} \mathrm{~N}_{2}[\mathrm{M}+\mathrm{H}]^{+}$ 663.3640, found 663.3637.
$(3 R, 3 a S, 6 a R, 8 S, 9 a R, 9 b S)-3-((4-(((3 R, 3 a S, 6 a R, 8 S, 9 a R, 9 b S)-8-$ Hydroxy-6,9-dimethyl-ene-2-oxododecahydroazuleno[4,5-b] furan-3-yl)methyl)piperazin-1-yl)methyl)-6,9-dimethyl-ene-2oxododeca hydroazuleno[4,5-b]furan-8-yl acetate (16)

Pale yellow viscous liquid $(15 \%) ; R_{\mathrm{f}} 0.30$ (EtOAc-petroleum ether, $7: 3) ;[\alpha]_{\mathrm{D}}^{26}+69.0\left(c 1, \mathrm{CHCl}_{3}\right) ;{ }^{1} \mathrm{H} \mathrm{NMR}\left(200 \mathrm{MHz}, \mathrm{CDCl}_{3}\right)$ $\delta_{\mathrm{H}} 5.58-5.52(\mathrm{~m}, 1 \mathrm{H}), 5.42-5.37(\mathrm{~m}, 2 \mathrm{H}), 5.32-5.26(\mathrm{~m}, 2 \mathrm{H}), 4.97$ $(\mathrm{s}, 1 \mathrm{H}), 4.94-4.91(\mathrm{~m}, 2 \mathrm{H}), 4.56(\mathrm{t}, J=7.6 \mathrm{~Hz}, 1 \mathrm{H}), 4.08-3.96(\mathrm{~m}$, $2 \mathrm{H}), 3.48-3.40(\mathrm{~m}, 3 \mathrm{H}), 2.97-2.85(\mathrm{~m}, 2 \mathrm{H}), 2.83-2.76(\mathrm{~m}, 3 \mathrm{H})$, 2.64-2.56 (m, 2H), 2.54-2.45 (m, 6H), 2.44-2.35 (m, 4H), 2.35$2.30(\mathrm{~m}, 2 \mathrm{H}), 2.27-2.14(\mathrm{~m}, 2 \mathrm{H}), 2.11(\mathrm{~s}, 3 \mathrm{H}), 2.09-2.01(\mathrm{~m}, 2 \mathrm{H})$, 1.84-1.71 (m, 2H), 1.39-1.33 (m, 6H); ${ }^{13} \mathrm{C}$ NMR (100 MHz, $\left.\mathrm{CDCl}_{3}\right) \delta_{\mathrm{C}} 177.4,177.3,170.8,153.4,148.9,148.8,148.4,113.5$, 113.5, 113.3, 111.0, 83.9, 83.8, 74.8, 73.6, 58.6, 57.6, 57.5, 53.5, 50.1, 49.8, 48.2, 47.8, 45.2, 44.1, 43.8, 38.9, 36.4, 36.2, 36.0, 32.8, 21.3, 8.3; LCMS (ESI): $m / z 643.38(\mathrm{M}+\mathrm{Na})^{+}$; HRMS (ESI) calcd for $\mathrm{C}_{36} \mathrm{H}_{49} \mathrm{O}_{7} \mathrm{~N}_{2}[\mathrm{M}+\mathrm{H}]^{+}$621.3534, found 621.3508.

\section{(3R,3aS,6aR,8S,9aR,9bS)-6,9-Dimethylene-3-}

(morpholinomethyl)-2-oxododecahydroazuleno[4,5-b]furan-8yl acetate (17)

Brown viscous liquid (84\%); $R_{\mathrm{f}} 0.50$ (EtOAc-petroleum ether, $7: 3) ;[\alpha]_{\mathrm{D}}^{26}+69.7\left(c 1, \mathrm{CHCl}_{3}\right) ;{ }^{1} \mathrm{H} \mathrm{NMR}\left(400 \mathrm{MHz}, \mathrm{CDCl}_{3}\right) \delta_{\mathrm{H}}$ 5.59-5.52 (m, 1H), $5.41(\mathrm{~m}, 1 \mathrm{H}), 5.28(\mathrm{~m}, 1 \mathrm{H}), 4.94-4.90(\mathrm{~m}, 2 \mathrm{H})$, $4.02(\mathrm{t}, J=9.8 \mathrm{~Hz}, 1 \mathrm{H}), 3.73-3.64(\mathrm{~m}, 4 \mathrm{H}), 2.97-2.89(\mathrm{~m}, 1 \mathrm{H})$, 2.84-2.76 (m, 2H), 2.65-2.58 (m, 1H), 2.53-2.40 (m, 7H), 2.39$2.32(\mathrm{~m}, 1 \mathrm{H}), 2.23(\mathrm{dq}, J=11.5,3.4 \mathrm{~Hz} 1 \mathrm{H}), 2.11(\mathrm{~s}, 3 \mathrm{H}), 2.08-$ $2.03(\mathrm{~m}, 1 \mathrm{H}), 1.81$ (quint, $J=6.9 \mathrm{~Hz}, 1 \mathrm{H}), 1.40-1.29(\mathrm{~m}, 1 \mathrm{H}) ;{ }^{13} \mathrm{C}$ NMR $\left(100 \mathrm{MHz}, \mathrm{CDCl}_{3}\right) \delta_{\mathrm{C}} 177.1,170.8,148.6,148.3,113.5$, 113.4, 83.7, 74.7, 66.9, 58.0, 54.0, 50.1, 47.8, 44.9, 44.1, 36.3, 36.1, 32.7, 21.3; LCMS (ESI): $m / z 398.07$ (M + Na) ${ }^{+}$; HRMS (ESI) calcd for $\mathrm{C}_{21} \mathrm{H}_{30} \mathrm{O}_{5} \mathrm{~N}[\mathrm{M}+\mathrm{H}]^{+}$376.2118, found 376.2115.

$(3 R, 3 a S, 6 a R, 8 S, 9 a R, 9 b S)-8-H y d r o x y-6,9-d i m e t h y l e n e-3-$ (morpholinomethyl)decahydroazuleno[4,5-b]furan-2(3H)-one (18)

Brown viscous liquid (14\%); $R_{\mathrm{f}} 0.40$ (EtOAc-petroleum ether, $7: 3) ;[\alpha]_{\mathrm{D}}^{26}+66.1\left(c 1, \mathrm{CHCl}_{3}\right) ;{ }^{1} \mathrm{H}$ NMR $\left(500 \mathrm{MHz}, \mathrm{CDCl}_{3}\right) \delta_{\mathrm{H}} 5.39$ $(\mathrm{s}, 1 \mathrm{H}), 5.31(\mathrm{~s}, 1 \mathrm{H}), 4.97(\mathrm{~s}, 1 \mathrm{H}), 4.93(\mathrm{~s}, 1 \mathrm{H}), 4.56(\mathrm{t}, J=7.3 \mathrm{~Hz}$, $1 \mathrm{H}), 4.05(\mathrm{t}, J=9.5 \mathrm{~Hz}, 1 \mathrm{H}), 3.71-3.65(\mathrm{~m}, 4 \mathrm{H}), 3.45(\mathrm{q}, J=$ $7.0 \mathrm{~Hz}, 1 \mathrm{H}), 2.88(\mathrm{q}, J=8.2 \mathrm{~Hz}, 1 \mathrm{H}), 2.83-2.76(\mathrm{~m}, 2 \mathrm{H}), 2.64-2.57$ (m, 1H), 2.53-2.41 (m, 5H), 2.37-2.32 (m, 2H), 2.24-2.18 (m, $1 \mathrm{H}), 2.08-2.02(\mathrm{~m}, 1 \mathrm{H}), 1.81-1.71(\mathrm{~m}, 1 \mathrm{H}), 1.38-1.32(\mathrm{~m}, 2 \mathrm{H})$; ${ }^{13} \mathrm{C}$ NMR $\left(125 \mathrm{MHz}, \mathrm{CDCl}_{3}\right) \delta_{\mathrm{C}} ; 177.3,153.3,148.8,113.5,111.1$, 83.8, 73.6, 66.9, 58.0, 54.1, 49.7, 48.2, 45.0, 43.7, 38.8, 35.9, 32.8; LCMS (ESI): $m / z 356.06(\mathrm{M}+\mathrm{Na})^{+}$; HRMS (ESI) calcd for $\mathrm{C}_{19} \mathrm{H}_{28} \mathrm{O}_{4} \mathrm{~N}[\mathrm{M}+\mathrm{H}]^{+}$334.2013, found 334.2013.

$(3 R, 3 a S, 6 a R, 8 S, 9 a R, 9 b S)$-8-Hydroxy-6,9-dimethylene-3(pyrrolidin-1-ylmethyl)decahydroazuleno[4,5-b]furan-2(3H)one (19)

Brown viscous liquid (78\%); $R_{\mathrm{f}} 0.20$ (EtOAc); $[\alpha]_{\mathrm{D}}^{26}+42.0(c 1$, $\left.\mathrm{CHCl}_{3}\right) ;{ }^{1} \mathrm{H}$ NMR $\left(500 \mathrm{MHz}, \mathrm{CDCl}_{3}\right) \delta_{\mathrm{H}} 5.39-5.26(\mathrm{~m}, 2 \mathrm{H}), 5.00-$ $4.88(\mathrm{~m}, 2 \mathrm{H}), 4.14-3.95(\mathrm{~m}, 1 \mathrm{H}), 3.55-3.36(\mathrm{~m}, 1 \mathrm{H}), 2.93-2.78$ (m, 4H), 2.76-2.68 (m, 1H), 2.66-2.59 (m, 2H), 2.54-2.44 (m, 
2H), 2.38-2.21 (m, 3H), 2.09-1.99 (m, 2H), 1.99-1.92 (m, 1H), 1.91-1.84 (m, 1H), 1.82-1.77 (m, 2H), 1.76-1.70 (m, 1H), 1.52 (d, $J=6.8 \mathrm{~Hz}, 1 \mathrm{H}), 1.42-1.30(\mathrm{~m}, 1 \mathrm{H}) ;{ }^{13} \mathrm{C} \mathrm{NMR}\left(125 \mathrm{MHz}, \mathrm{CDCl}_{3}\right)$ $\delta_{\mathrm{C}} 177.3,153.3,148.9,113.4,110.8,83.9,73.5,54.5,54.4,49.6$, 47.7, 46.3, 43.5, 38.8, 36.2, 32.6, 23.5; LCMS (ESI): $m / z 318.18$ (M $+\mathrm{H})^{+}$; HRMS (ESI) calcd for $\mathrm{C}_{19} \mathrm{H}_{28} \mathrm{O}_{3} \mathrm{~N}[\mathrm{M}+\mathrm{H}]^{+} 318.2064$, found 318.2060 .

$(3 R, 3 a S, 6 a R, 8 S, 9 a R, 9 b S)-8-H y d r o x y-6,9-d i m e t h y l e n e-3-$ (piperidin-1-ylmethyl)decahydroazuleno[4,5-b]furan-2(3H)one (20)

Dark brown viscous liquid (66\%); $R_{\mathrm{f}} 0.30$ (EtOAc); $[\alpha]_{\mathrm{D}}^{26}+46.1(c$ 1, $\left.\mathrm{CHCl}_{3}\right) ;{ }^{1} \mathrm{H} \mathrm{NMR}\left(400 \mathrm{MHz}, \mathrm{CDCl}_{3}\right) \delta_{\mathrm{H}} 5.37(\mathrm{~d}, J=1.8 \mathrm{~Hz}, 1 \mathrm{H})$, $5.30(\mathrm{~d}, J=1.8 \mathrm{~Hz}, 1 \mathrm{H}), 4.96(\mathrm{~s}, 1 \mathrm{H}), 4.93(\mathrm{~s}, 1 \mathrm{H}), 4.55(\mathrm{dt}, J=7.3$, 1.4, Hz, 1H), 4.06 (dt, $J=9.6,1.8 \mathrm{~Hz}, 1 \mathrm{H}), 2.92-2.75(\mathrm{~m}, 3 \mathrm{H})$, 2.70-2.63 (m, 1H), 2.61-2.53 (m, 3H), 2.52-2.46 (m, 3H), 2.38$2.29(\mathrm{~m}, 2 \mathrm{H}), 2.22-2.10(\mathrm{~m}, 1 \mathrm{H}), 2.08-1.98$ (m, 2H), 1.79-1.71 (m, 1H), 1.65-1.57 (m, 4H), 1.50-1.42 (m, 2H), 1.38-1.32 (m, $1 \mathrm{H}) ;{ }^{13} \mathrm{C} \mathrm{NMR}\left(100 \mathrm{MHz}, \mathrm{CDCl}_{3}\right) \delta_{\mathrm{C}} 177.6,153.4,149.0,113.5$, 110.9, 84.0, 73.6, 57.7, 54.6, 49.7, 48.3, 44.7, 43.6, 38.8, 36.1, 32.5, 29.8, 25.3, 23.8; LCMS (ESI): $m / z 354.14(\mathrm{M}+\mathrm{Na})^{+}$; HRMS (ESI) calcd for $\mathrm{C}_{20} \mathrm{H}_{30} \mathrm{O}_{3} \mathrm{~N}[\mathrm{M}+\mathrm{H}]^{+} 332.2220$, found 332.2219.

Methyl(((3R,3aS,6aR,8S,9aR,9bS)-8-hydroxy-6,9-dimethylene2-oxododecahydroazuleno[4,5-b]furan-3-yl)methyl)-L-leucinate (21)

Yellow viscous liquid (82\%); $R_{\mathrm{f}} 0.30$ (EtOAc-petroleum ether, $1: 1) ;[\alpha]_{\mathrm{D}}^{25}+29.8\left(c 1, \mathrm{CHCl}_{3}\right) ;{ }^{1} \mathrm{H}$ NMR $\left(400 \mathrm{MHz}, \mathrm{CDCl}_{3}\right) \delta_{\mathrm{H}} 5.37$ $(\mathrm{s}, 1 \mathrm{H}), 5.30(\mathrm{~s}, 1 \mathrm{H}), 4.97(\mathrm{~s}, 1 \mathrm{H}), 4.93(\mathrm{~s}, 1 \mathrm{H}), 4.55(\mathrm{t}, J=7.8 \mathrm{~Hz}$, $1 \mathrm{H}), 4.05(\mathrm{t}, J=9.6 \mathrm{~Hz}, 1 \mathrm{H}), 3.72(\mathrm{~s}, 3 \mathrm{H}), 3.30(\mathrm{t}, J=7.3 \mathrm{~Hz}, 1 \mathrm{H})$, 2.91-2.84 (m, 2H), 2.84-2.77 (m, 1H), $2.72(\mathrm{dd}, J=11.9,4.6 \mathrm{~Hz}$, $1 \mathrm{H}), 2.50(\mathrm{td}, J=13.3,4.6 \mathrm{~Hz}, 1 \mathrm{H}), 2.44-2.26(\mathrm{~m}, 3 \mathrm{H}), 2.26-2.11$ $(\mathrm{m}, 2 \mathrm{H}), 2.06-1.98(\mathrm{~m}, 1 \mathrm{H}), 1.79-1.67(\mathrm{~m}, 2 \mathrm{H}), 1.43-1.28(\mathrm{~m}$, $2 \mathrm{H}), 1.53-1.43(\mathrm{~m}, 2 \mathrm{H}), 0.94-0.88(\mathrm{~m}, 6 \mathrm{H}) ;{ }^{13} \mathrm{C}$ NMR $(100 \mathrm{MHz}$, $\left.\mathrm{CDCl}_{3}\right) \delta_{\mathrm{C}} 177.4,176.1,153.4,148.8,113.7,111.1,84.1,73.6$, 60.7, 51.8, 49.7, 48.0, 46.1, 46.0, 43.7, 42.6, 38.9, 35.9, 32.5, 25.0, 22.8, 22.3; LCMS (ESI): $m / z 414.27$ (M + Na) ${ }^{+}$; HRMS (ESI) calcd for $\mathrm{C}_{22} \mathrm{H}_{34} \mathrm{O}_{5} \mathrm{~N}[\mathrm{M}+\mathrm{H}]^{+}$392.2431, found 392.2434.

(3R,3aS,6aR,8S,9aR,9bS)-8-Hydroxy-3-(methoxymethyl)-6,9dimethylenedecahydroazuleno[4,5-b]furan-2(3H)-one (22)

Yellow viscous liquid (87\%); $R_{\mathrm{f}} 0.40$ (EtOAc-petroleum ether, $1: 1) ;[\alpha]_{\mathrm{D}}^{26}+62.4\left(c 1, \mathrm{CHCl}_{3}\right) ;{ }^{1} \mathrm{H} \mathrm{NMR}\left(400 \mathrm{MHz}, \mathrm{CDCl}_{3}\right) \delta_{\mathrm{H}} 5.38$ $(\mathrm{m}, 1 \mathrm{H}), 5.30(\mathrm{~m}, 1 \mathrm{H}), 4.97(\mathrm{~m}, 1 \mathrm{H}), 4.93(\mathrm{~m}, 1 \mathrm{H}), 4.55(\mathrm{t}, J=$ $7.3 \mathrm{~Hz}, 1 \mathrm{H}), 4.05(\mathrm{t}, J=8.7 \mathrm{~Hz}, 1 \mathrm{H}), 3.73-3.68(\mathrm{~m}, 1 \mathrm{H}), 3.63(\mathrm{dd}, J$ $=9.6,1.8 \mathrm{~Hz}, 1 \mathrm{H}), 3.37(\mathrm{~s}, 3 \mathrm{H}), 2.93-2.80(\mathrm{~m}, 2 \mathrm{H}), 2.51(\mathrm{td}, J=$ 12.8, 4.6 Hz, 1H), 2.42-2.29 (m, 3H), 2.24-2.16 (m, 1H), 2.09$2.01(\mathrm{~m}, 1 \mathrm{H}), 1.80-1.71(\mathrm{~m}, 1 \mathrm{H}), 1.42-1.28(\mathrm{~m}, 2 \mathrm{H}) ;{ }^{13} \mathrm{C}$ NMR $\left(100 \mathrm{MHz}, \mathrm{CDCl}_{3}\right) \delta_{\mathrm{C}} 176.1,153.4,148.9,113.7,110.9,84.1,73.6$, 68.9, 59.4, 49.5, 48.1 45.1, 43.6, 38.9, 36.2, 32.6; LCMS (ESI): $\mathrm{m} / \mathrm{z}$ $300.99(\mathrm{M}+\mathrm{Na})^{+}$; HRMS (ESI) calcd for $\mathrm{C}_{16} \mathrm{H}_{22} \mathrm{O}_{4} \mathrm{Na}[\mathrm{M}+\mathrm{Na}]^{+}$ 301.1410, found 301.1398.
(3aS,6aR,8S,9aR,9bS)-3-((E)-4-Methylbenzylidene)-6,9dimethylene-2-oxododecahydroazuleno $[4,5-b]$ furan-8-yl acetate (23)

Brown viscous liquid (48\%); $R_{\mathrm{f}} 0.45$ (EtOAc-petroleum ether, $1: 4) ;{ }^{1} \mathrm{H} \mathrm{NMR}\left(500 \mathrm{MHz}, \mathrm{CDCl}_{3}\right) \delta_{\mathrm{H}} 7.63(\mathrm{~d}, J=2.7 \mathrm{~Hz}, 1 \mathrm{H}), 7.30$ $(\mathrm{d}, J=7.9 \mathrm{~Hz}, 2 \mathrm{H}), 7.24(\mathrm{~d}, J=7.9 \mathrm{~Hz}, 2 \mathrm{H}), 5.61(\mathrm{t}, J=7.2 \mathrm{~Hz}$, $1 \mathrm{H}), 5.56(\mathrm{~s}, 1 \mathrm{H}), 5.33(\mathrm{~s}, 1 \mathrm{H}), 5.01(\mathrm{~s}, 1 \mathrm{H}), 4.94(\mathrm{~s}, 1 \mathrm{H}), 4.21(\mathrm{dd}, J$ $=9.9,8.1 \mathrm{~Hz}, 1 \mathrm{H}), 3.41(\mathrm{td}, J=7.4,3.8 \mathrm{~Hz}, 1 \mathrm{H}), 3.03(\mathrm{q}, J=$ $8.2 \mathrm{~Hz}, 1 \mathrm{H}), 2.95-2.83(\mathrm{~m}, 1 \mathrm{H}), 2.49-2.44(\mathrm{~m}, 1 \mathrm{H}), 2.42(\mathrm{~s}, 3 \mathrm{H})$, 2.37-2.29 (m, 2H), 2.21-2.15 (m, 1H), 2.14 (s, 3H), 1.89-1.81 (m, $1 \mathrm{H}) ;{ }^{13} \mathrm{C}$ NMR $\left(125 \mathrm{MHz}, \mathrm{CDCl}_{3}\right) \delta_{\mathrm{C}} 171.8,170.9,148.0,147.5$, 139.9, 138.1, 131.0, 129.7, 129.3, 128.4, 114.7, 113.8, 83.7, 74.7, 50.6, 45.2, 43.5, 36.7 33.3, 28.4, 21.5, 21.3; HRMS (ESI) calcd for $\mathrm{C}_{24} \mathrm{H}_{26} \mathrm{O}_{4} \mathrm{Na}[\mathrm{M}+\mathrm{Na}]^{+}$401.1723, found 401.1720.

(3aS,6aR,8S,9aR,9bS)-6,9-Dimethylene-2-oxo-3-((E)-3(trifluoro-methyl)benzylidene)dodecahydroazuleno[4,5- $b]$ furan-8-yl acetate (24)

Brown viscous liquid (53\%); $R_{\mathrm{f}} 0.42$ (EtOAc-petroleum ether, $1: 4) ;{ }^{1} \mathrm{H}$ NMR $\left(400 \mathrm{MHz}, \mathrm{CDCl}_{3}\right) \delta_{\mathrm{H}} 7.67-7.61(\mathrm{~m}, 3 \mathrm{H}), 7.57-$ $7.54(\mathrm{~m}, 2 \mathrm{H}), 5.63-5.56(\mathrm{~m}, 1 \mathrm{H}), 5.56-5.53(\mathrm{~m}, 1 \mathrm{H}), 5.35-5.31$ $(\mathrm{m}, 1 \mathrm{H}), 5.01(\mathrm{~s}, 1 \mathrm{H}), 4.92(\mathrm{~s}, 1 \mathrm{H}), 4.23(\mathrm{dd}, J=10.4,7.7 \mathrm{~Hz}, 1 \mathrm{H})$, $3.42(\mathrm{td}, J=7.5,3.8 \mathrm{~Hz}, 1 \mathrm{H}), 3.03$ (q, $J=8.3 \mathrm{~Hz}, 1 \mathrm{H}), 2.91-2.82$ (m, 1H), $2.43(\mathrm{dt}, J=14.2,8.0 \mathrm{~Hz}, 1 \mathrm{H}), 2.34-2.21(\mathrm{~m}, 3 \mathrm{H}), 2.19-$ $2.13(\mathrm{~m}, 1 \mathrm{H}), 2.11(\mathrm{~s}, 3 \mathrm{H}), 1.87-1.78(\mathrm{~m}, 1 \mathrm{H}) ;{ }^{13} \mathrm{C} \mathrm{NMR}(100 \mathrm{MHz}$, $\left.\mathrm{CDCl}_{3}\right) \delta_{\mathrm{C}} 170.9,170.8,147.9,146.9,135.9,134.7,132.8,131.7$, 129.2, 128.6, 125.9, 125.9, 122.4, 115.1, 114.2, 83.6, 74.6, 50.6, 45.3, 43.3, 36.7, 32.3, 28.1, 21.3; HRMS (ESI) calcd for $\mathrm{C}_{24} \mathrm{H}_{23} \mathrm{O}_{4} \mathrm{~F}_{3} \mathrm{Na}[\mathrm{M}+\mathrm{Na}]^{+} 455.1441$, found 455.1436 .

(3aS,6aR,8S,9aR,9bS)-3-((E)-4-Chlorobenzylidene)-6,9dimethylene -2-oxododecahydroazuleno[4,5-b]furan-8-yl acetate (25)

Brown viscous liquid (64\%); $R_{\mathrm{f}} 0.42$ (EtOAc-petroleum ether, $1: 4) ;{ }^{1} \mathrm{H}$ NMR $\left(400 \mathrm{MHz}, \mathrm{CDCl}_{3}\right) \delta_{\mathrm{H}} 7.60-7.54(\mathrm{~m}, 1 \mathrm{H}), 7.39(\mathrm{~d}, J$ $=8.1 \mathrm{~Hz}, 2 \mathrm{H}), 7.31(\mathrm{~d}, J=8.1 \mathrm{~Hz}, 2 \mathrm{H}), 5.59(\mathrm{t}, J=7.1 \mathrm{~Hz}, 1 \mathrm{H})$, $5.53(\mathrm{~s}, 1 \mathrm{H}), 5.32(\mathrm{~s}, 1 \mathrm{H}), 4.99(\mathrm{~s}, 1 \mathrm{H}), 4.92(\mathrm{~s}, 1 \mathrm{H}), 4.24-4.17(\mathrm{~m}$, $1 \mathrm{H}), 3.39-3.30(\mathrm{~m}, 1 \mathrm{H}), 3.01(\mathrm{q}, J=8.1 \mathrm{~Hz}, 1 \mathrm{H}), 2.85(\mathrm{t}, J=$ $9.3 \mathrm{~Hz}, 1 \mathrm{H}), 2.48-2.38(\mathrm{~m}, 1 \mathrm{H}), 2.36-2.26(\mathrm{~m}, 2 \mathrm{H}), 2.20-2.14(\mathrm{~m}$, 1H), $2.11(\mathrm{~s}, 3 \mathrm{H}), 1.87-1.77(\mathrm{~m}, 1 \mathrm{H}) ;{ }^{13} \mathrm{C} \mathrm{NMR}\left(100 \mathrm{MHz}, \mathrm{CDCl}_{3}\right)$ $\delta_{\mathrm{C}} 171.3,170.8,147.9,147.2,136.5,135.4,132.4,130.8,130.3$, 128.9, 115.0, 114.1, 83.5, 74.6, 50.6, 45.2, 43.4, 36.7, 32.9, 28.3, 21.3; HRMS (ESI) calcd for $\mathrm{C}_{23} \mathrm{H}_{23} \mathrm{O}_{4} \mathrm{ClNa}[\mathrm{M}+\mathrm{Na}]^{+} 421.1177$, found 421.1171 .

(3aS,6aR,8S,9aR,9bS)-3-((E)-2-Methoxy-6-nitrobenzylidene)6,9-dimethylene-2-oxododecahydroazuleno[4,5-b]furan-8-yl acetate (26)

Brown viscous liquid (42\%); $R_{\mathrm{f}} 0.37$ (EtOAc-petroleum ether, $3: 7) ;{ }^{1} \mathrm{H} \mathrm{NMR}\left(400 \mathrm{MHz}, \mathrm{CDCl}_{3}\right) \delta_{\mathrm{H}} 7.67(\mathrm{~d}, J=7.8 \mathrm{~Hz}, 1 \mathrm{H}), 7.42$ $(\mathrm{t}, J=8.3 \mathrm{~Hz}, 1 \mathrm{H}), 7.15(\mathrm{~d}, J=8.1 \mathrm{~Hz}, 1 \mathrm{H}), 6.86(\mathrm{brs}, 1 \mathrm{H}), 5.56(\mathrm{t}$, $J=7.3 \mathrm{~Hz}, 1 \mathrm{H}), 5.45(\mathrm{~s}, 1 \mathrm{H}), 5.27(\mathrm{~s}, 1 \mathrm{H}), 4.98(\mathrm{~s}, 2 \mathrm{H}), 4.10(\mathrm{t}, J=$ $9.5 \mathrm{~Hz}, 1 \mathrm{H}), 3.83(\mathrm{~s}, 3 \mathrm{H}), 3.11-3.01(\mathrm{~m}, 1 \mathrm{H}), 2.97(\mathrm{q}, J=8.1 \mathrm{~Hz}$, $1 \mathrm{H}), 2.90-2.82(\mathrm{~m}, 1 \mathrm{H}), 2.57-2.50(\mathrm{~m}, 1 \mathrm{H}), 2.48-2.36(\mathrm{~m}, 2 \mathrm{H})$, 2.28-2.19 (m, 1H), 2.11 (s, 3H), 1.86-1.78 (m, 1H), 1.64-1.53 (m, 
$1 \mathrm{H}) ;{ }^{13} \mathrm{C} \mathrm{NMR}\left(100 \mathrm{MHz}, \mathrm{CDCl}_{3}\right) \delta_{\mathrm{C}} 170.9,170.9,148.6,148.0$, 147.8, 132.4, 129.3, 122.7, 119.7, 116.4, 115.4, 114.3, 113.7, 83.1, 74.7, 56.5, 50.3, 46.4, 44.7, 36.5, 34.3, 30.6, 21.3; HRMS (ESI) calcd for $\mathrm{C}_{24} \mathrm{H}_{25} \mathrm{O}_{7} \mathrm{NNa}[\mathrm{M}+\mathrm{Na}]^{+} 462.1523$, found 462.1521 .

(3aS,6aR,8S,9aR,9bS)-3-((E)-4-Methyl-3-nitrobenzylidene)-6,9dimethylene-2-oxododecahydroazuleno[4,5-b]furan-8-yl acetate (27)

Light brown semi solid (54\%); $R_{\mathrm{f}} 0.56$ (EtOAc-petroleum ether, $3: 7) ;{ }^{1} \mathrm{H}$ NMR (400 MHz, $\left.\mathrm{CDCl}_{3}\right) \delta_{\mathrm{H}} 8.00(\mathrm{~s}, 1 \mathrm{H}), 7.57$ (d, $J=$ $3.4 \mathrm{~Hz}, 1 \mathrm{H}), 7.53-7.48(\mathrm{~m}, 1 \mathrm{H}), 7.41(\mathrm{~d}, J=7.8 \mathrm{~Hz}, 1 \mathrm{H}), 5.63-5.55$ $(\mathrm{m}, 1 \mathrm{H}), 5.55-5.51(\mathrm{~m}, 1 \mathrm{H}), 5.32(\mathrm{t}, J=1.7 \mathrm{~Hz}, 1 \mathrm{H}), 5.02(\mathrm{~s}, 1 \mathrm{H})$, 4.96 (s, 1H), 4.23 (dd, $J=10.4,7.7 \mathrm{~Hz}, 1 \mathrm{H}), 3.47-3.39(\mathrm{~m}, 1 \mathrm{H})$, 3.10-2.94 (m, 1H), 2.93-2.80 (m, 1H), $2.65(\mathrm{~s}, 3 \mathrm{H}), 2.49-2.38(\mathrm{~m}$, $1 \mathrm{H}), 2.38-2.26$ (m, 2H), 2.26-2.15 (m, 1H), 2.11 (s, 3H), 1.87-1.78 $(\mathrm{m}, 1 \mathrm{H}) ;{ }^{13} \mathrm{C}$ NMR $\left(100 \mathrm{MHz}, \mathrm{CDCl}_{3}\right) \delta_{\mathrm{C}} 170.8,170.8,149.1$, $147.9,146.9,134.7,133.9,133.2$, 132.6, 131.9, 126.6, 125.1, 115.3, 114.1, 83.6, 74.6, 50.6, 45.2, 43.3, 36.6, 32.5, 28.2, 21.2, 20.5; HRMS (ESI) calcd for $\mathrm{C}_{24} \mathrm{H}_{25} \mathrm{O}_{6} \mathrm{NNa}[\mathrm{M}+\mathrm{Na}]^{+}$446.1574, found 446.1569 .

(3aS,6aR,8S,9aR,9bS)-3-((E)-4-Acetamido-3-(trifluoromethyl) benzylidene)-6,9-dimethylene-2-oxododecahydroazuleno[4,5b] furan-8-yl acetate (28)

Brown viscous liquid (68\%); $R_{\mathrm{f}} 0.15$ (EtOAc-petroleum ether, $3: 7) ;{ }^{1} \mathrm{H}$ NMR $\left(500 \mathrm{MHz}, \mathrm{CDCl}_{3}\right) \delta_{\mathrm{H}} 8.37(\mathrm{~d}, J=7.9 \mathrm{~Hz}, 1 \mathrm{H}), 7.62$ (s, 1H), 7.59-7.53 (m, 3H), 5.62-5.56 (m, 1H), $5.54(\mathrm{~s}, 1 \mathrm{H}), 5.34-$ $5.31(\mathrm{~m}, 1 \mathrm{H}), 5.02(\mathrm{~s}, 1 \mathrm{H}), 4.94(\mathrm{~s}, 1 \mathrm{H}), 4.23(\mathrm{dd}, J=10.4,7.6 \mathrm{~Hz}$, $1 \mathrm{H}), 3.40$ (dt, $J=7.6,3.7 \mathrm{~Hz}, 1 \mathrm{H}), 3.03$ (q, $J=8.2 \mathrm{~Hz}, 1 \mathrm{H}), 2.90-$ $2.82(\mathrm{~m}, 1 \mathrm{H}), 2.43(\mathrm{td}, J=14.0,8.1 \mathrm{~Hz}, 1 \mathrm{H}), 2.35-2.29(\mathrm{~m}, 2 \mathrm{H})$, $2.26(\mathrm{~s}, 3 \mathrm{H}), 2.24-2.15(\mathrm{~m}, 2 \mathrm{H}), 2.12(\mathrm{~s}, 3 \mathrm{H}), 1.87-1.79(\mathrm{~m}, 1 \mathrm{H})$; ${ }^{13} \mathrm{C} \mathrm{NMR}\left(100 \mathrm{MHz}, \mathrm{CDCl}_{3}\right) \delta_{\mathrm{C}} 171.1,170.8,168.5,147.9,147.0$, 136.0, 135.4, 133.9, 130.7, 127.4, 123.8, 115.2, 114.1, 83.6, 74.6, 50.6, 45.3, 43.2 , 36.7, 32.4 , 28.1, 24.9, 21.3; HRMS (ESI) calcd for $\mathrm{C}_{26} \mathrm{H}_{26} \mathrm{O}_{5} \mathrm{NF}_{3} \mathrm{Na}[\mathrm{M}+\mathrm{Na}]^{+}$512.1655, found 512.1650.

(3aS,6aR,8S,9aR,9bS)-3-((E)-2-Methylbenzylidene)-6,9dimethylene-2-oxododecahydroazuleno[4,5-b]furan-8-yl acetate (29)

Brown viscous liquid (56\%); $R_{\mathrm{f}} 0.45$ (EtOAc-petroleum ether, $1: 4) ;{ }^{1} \mathrm{H}$ NMR (500 MHz, $\left.\mathrm{CDCl}_{3}\right) \delta_{\mathrm{H}} 7.73(\mathrm{~d}, J=3.4 \mathrm{~Hz}, 1 \mathrm{H})$, 7.27-7.16 (m, 4H), 5.62-5.55 (m, 1H), $5.53(\mathrm{t}, J=2.0 \mathrm{~Hz}, 1 \mathrm{H})$, $5.32(\mathrm{t}, J=1.8 \mathrm{~Hz}, 1 \mathrm{H}), 4.94(\mathrm{~s}, 1 \mathrm{H}), 4.88-4.82(\mathrm{~m}, 1 \mathrm{H}), 4.17(\mathrm{dd}, J$ $=10.4,8.2 \mathrm{~Hz}, 1 \mathrm{H}), 3.33-3.23(\mathrm{~m}, 1 \mathrm{H}), 2.97(\mathrm{q}, J=8.0 \mathrm{~Hz}, 1 \mathrm{H})$, 2.89-2.81 (m, 1H), 2.44-2.38 (m, 1H), 2.31 (s, 3H), 2.27-2.15 (m, $2 \mathrm{H}), 2.11(\mathrm{~s}, 3 \mathrm{H}), 2.06-2.00(\mathrm{~m}, 2 \mathrm{H}), 1.84-1.76(\mathrm{~m}, 1 \mathrm{H}) ;{ }^{13} \mathrm{C}$ NMR $\left(125 \mathrm{MHz}, \mathrm{CDCl}_{3}\right) \delta_{\mathrm{C}} 171.4,170.9,148.0,147.4,137.5,136.9$, 133.4, 130.6, 130.3, 129.3, 127.9, 125.7, 114.6, 114.1, 83.4, 74.7, 50.7, 45.1, 43.9, 36.6, 33.0, 28.7, 21.3, 19.9; HRMS (ESI) calcd for $\mathrm{C}_{24} \mathrm{H}_{26} \mathrm{O}_{4} \mathrm{Na}[\mathrm{M}+\mathrm{Na}]^{+}$401.1723, found 401.1718.
Methyl-4-((E)-((3aS,6aR,8S,9aR,9bS)-8-acetoxy-6,9-

dimethylene-2-oxodecahydroazuleno[4,5-b]furan-3(2H)ylidene)methyl)benzoate (30)

Brown viscous liquid (67\%); $R_{\mathrm{f}} 0.24$ (EtOAc-petroleum ether, $1: 4) ;{ }^{1} \mathrm{H}$ NMR $\left(400 \mathrm{MHz}, \mathrm{CDCl}_{3}\right) \delta_{\mathrm{H}}$ 8.07-8.02 (m, 1H), 7.58$7.52(\mathrm{~m}, 1 \mathrm{H}), 7.48-7.43(\mathrm{~m}, 1 \mathrm{H}), 7.36-7.23(\mathrm{~m}, 2 \mathrm{H}), 5.60-5.51$ $(\mathrm{m}, 2 \mathrm{H}), 5.45$ (d, $J=11.2 \mathrm{~Hz}, 1 \mathrm{H}), 4.95-4.89$ (m, 2H), 4.17 (dd, $J$ $=10.3,8.3 \mathrm{~Hz}, 1 \mathrm{H}), 3.90(\mathrm{~s}, 3 \mathrm{H}), 3.24-3.17(\mathrm{~m}, 1 \mathrm{H}), 2.98-2.90$ (m, 1H), 2.86-2.78 (m, 1H), 2.59-2.51 (m, 1H), 2.47-2.32 (m, $2 \mathrm{H}), 2.21-2.12(\mathrm{~m}, 1 \mathrm{H}), 2.10(\mathrm{~s}, 3 \mathrm{H}), 2.01-1.93(\mathrm{~m}, 1 \mathrm{H}), 1.79-1.72$ $(\mathrm{m}, 1 \mathrm{H}) ;{ }^{13} \mathrm{C}$ NMR $\left(100 \mathrm{MHz}, \mathrm{CDCl}_{3}\right) \delta_{\mathrm{C}} 171.0,170.8,166.6$, $147.9,147.3,138.3,136.4,132.2$, 130.9, 129.3, 128.9, 128.8, 128.4, 114.5, 114.3, 83.0, 74.7, 52.4, 50.8, 45.2, 43.7, 36.6, 32.6, 29.0, 21.3; HRMS (ESI) calcd for $\mathrm{C}_{25} \mathrm{H}_{26} \mathrm{O}_{6} \mathrm{Na}[\mathrm{M}+\mathrm{Na}]^{+} 445.1622$, found 445.1616 .

(3aS,6aR,8S,9aR,9bS)-3-((E)-Benzylidene)-6,9-dimethylene-2oxo dodecahydroazuleno[4,5-b]furan-8-yl acetate (31)

Light brown viscous liquid (55\%); $R_{\mathrm{f}} 0.57$ (EtOAc-petroleum ether, $1: 4) ;{ }^{1} \mathrm{H}$ NMR (400 MHz, $\left.\mathrm{CDCl}_{3}\right) \delta_{\mathrm{H}} 7.41-7.36(\mathrm{~m}, 6 \mathrm{H})$, $5.63-5.56(\mathrm{~m}, 1 \mathrm{H}), 5.54(\mathrm{t}, J=2.0 \mathrm{~Hz}, 1 \mathrm{H}), 5.32(\mathrm{t}, J=2.0 \mathrm{~Hz}, 1 \mathrm{H})$, $4.98(\mathrm{~s}, 1 \mathrm{H}), 4.92(\mathrm{~s}, 1 \mathrm{H}), 4.20(\mathrm{dd}, J=10.3,7.8 \mathrm{~Hz}, 1 \mathrm{H}), 3.43-$ $3.35(\mathrm{~m}, 1 \mathrm{H}), 3.01(\mathrm{q}, J=8.1 \mathrm{~Hz}, 1 \mathrm{H}), 2.92-2.80(\mathrm{~m}, 1 \mathrm{H}), 2.48-$ $2.36(\mathrm{~m}, 2 \mathrm{H}), 2.33-2.27(\mathrm{~m}, 1 \mathrm{H}), 2.19-2.13(\mathrm{~m}, 1 \mathrm{H}), 2.11(\mathrm{~s}, 3 \mathrm{H})$, 1.96-1.89 (m, 1H), 1.87-1.78 (m, 1H); ${ }^{13} \mathrm{C}$ NMR (100 MHz, $\left.\mathrm{CDCl}_{3}\right) \delta_{\mathrm{C}} 171.6,170.9,148.0,147.4,138.0,133.9,129.6,129.4$, 128.6, 128.4, 114.8, 113.9, 83.6, 74.7, 50.6, 45.2, 43.5, 36.7, 33.1, 28.4, 21.3; HRMS (ESI) calcd for $\mathrm{C}_{23} \mathrm{H}_{24} \mathrm{O}_{4} \mathrm{Na}[\mathrm{M}+\mathrm{Na}]^{+} 387.1567$, found 387.1563 .

$(3 a S, 6 a R, 8 S, 9 a R, 9 b S)-6,9-D i m e t h y l e n e-3-((E)-2-$ nitrobenzylidene)-2-oxododecahydroazuleno[ $[4,5-b]$ furan-8-yl acetate (32)

Brown viscous liquid (47\%); $R_{\mathrm{f}} 0.20$ (EtOAc-petroleum ether, $1: 4) ;{ }^{1} \mathrm{H} \mathrm{NMR}\left(400 \mathrm{MHz}, \mathrm{CDCl}_{3}\right) \delta_{\mathrm{H}} 8.23-8.13(\mathrm{~m}, 1 \mathrm{H}), 7.87(\mathrm{~d}, J$ $=3.7 \mathrm{~Hz}, 1 \mathrm{H}), 7.73-7.65(\mathrm{~m}, 1 \mathrm{H}), 7.63-7.55(\mathrm{~m}, 1 \mathrm{H}), 7.42(\mathrm{~d}, J=$ $7.3 \mathrm{~Hz}, 1 \mathrm{H}), 5.59-5.51(\mathrm{~m}, 2 \mathrm{H}), 5.36-5.29(\mathrm{~m}, 1 \mathrm{H}), 4.93(\mathrm{~s}, 1 \mathrm{H})$, $4.81(\mathrm{~s}, 1 \mathrm{H}), 4.20(\mathrm{dd}, J=10.3,8.3 \mathrm{~Hz}, 1 \mathrm{H}), 3.24-3.12(\mathrm{~m}, 1 \mathrm{H})$, $2.94(\mathrm{q}, J=8.4 \mathrm{~Hz}, 1 \mathrm{H}), 2.87-2.77(\mathrm{~m}, 1 \mathrm{H}), 2.43-2.34(\mathrm{~m}, 1 \mathrm{H})$, 2.23-2.14 (m, 1H), 2.11 (s, 3H), 2.01-1.95 (m, 1H), 1.83-1.73 (m, $1 \mathrm{H}), 1.66-1.53(\mathrm{~m}, 2 \mathrm{H}) ;{ }^{13} \mathrm{C}$ NMR (100 MHz, $\left.\mathrm{CDCl}_{3}\right) \delta_{\mathrm{C}} 170.9$, $170.3,147.7$, 147.5, 146.9, 134.2, 133.6, 132.5, 130.8, 130.1, 129.9, 125.1, 114.9, 114.6, 82.9, 74.6, 50.7, 45.2, 43.7, 36.6, 32.2, 29.0, 21.3; HRMS (ESI) calcd for $\mathrm{C}_{23} \mathrm{H}_{23} \mathrm{O}_{6} \mathrm{NNa}[\mathrm{M}+\mathrm{Na}]^{+}$ 432.1418, found 432.1413 .

(3aS,6aR,8S,9aR,9bS)-3-((E)-4-Chloro-2-nitrobenzylidene)-6,9dimethylene-2-oxododecahydroazuleno $[4,5-b]$ furan-8-yl acetate (33)

Brown viscous liquid (52\%); $R_{\mathrm{f}} 0.26$ (EtOAc-petroleum ether, $1: 4) ;{ }^{1} \mathrm{H} \mathrm{NMR}\left(500 \mathrm{MHz}, \mathrm{CDCl}_{3}\right) \delta_{\mathrm{H}} 8.18(\mathrm{~d}, J=2.1 \mathrm{~Hz}, 1 \mathrm{H}), 7.78$ $(\mathrm{d}, J=3.7 \mathrm{~Hz}, 1 \mathrm{H}), 7.66(\mathrm{dd}, J=8.2,1.8 \mathrm{~Hz}, 1 \mathrm{H}), 7.37$ (d, $J=$ $8.2 \mathrm{~Hz}, 1 \mathrm{H}), 5.60-5.55(\mathrm{~m}, 1 \mathrm{H}), 5.52(\mathrm{t}, J=1.8 \mathrm{~Hz}, 1 \mathrm{H}), 5.33(\mathrm{t}, J=$ $1.8 \mathrm{~Hz}, 1 \mathrm{H}), 4.96-4.93(\mathrm{~m}, 1 \mathrm{H}), 4.84(\mathrm{~s}, 1 \mathrm{H}), 4.21$ (dd, $J=10.4$, 8.2 Hz, 1H), 3.19-3.12 (m, 1H), 2.98-2.92 (m, 1H), 2.84-2.77 (m, 
1H), 2.42-2.35 (m, 1H), 2.23-2.17 (m, 1H), 2.11 (s, 3H), 2.04-1.98 (m, 1H), 1.91-1.82 (m, 1H), 1.82-1.76 (m, 1H), 1.67-1.60 (m, $1 \mathrm{H}) ;{ }^{13} \mathrm{C} \mathrm{NMR}\left(125 \mathrm{MHz}, \mathrm{CDCl}_{3}\right) \delta_{\mathrm{C}} 170.8,170.0,147.9,147.6$, $146.7,135.8,133.7,133.3,132.8,131.2$, 129.1, 125.4, 115.1, 114.7, 82.8, 74.6, 50.8, 45.2, 43.7, 36.6, 32.0, 29.1, 21.3; HRMS (ESI) calcd for $\mathrm{C}_{23} \mathrm{H}_{22} \mathrm{O}_{6} \mathrm{NClNa}[\mathrm{M}+\mathrm{Na}]^{+} 466.1028$, found 466.1027 .

(3aS,6aR,8S,9aR,9bS)-3-((E)-4-Methyl-2-nitrobenzylidene)-6,9dimethylene-2-oxododecahydroazuleno[4,5-b]furan-8-yl acetate (34)

Brown viscous liquid (67\%); $R_{\mathrm{f}} 0.26$ (EtOAc-petroleum ether, $1: 4) ;{ }^{1} \mathrm{H}$ NMR $\left(400 \mathrm{MHz}, \mathrm{CDCl}_{3}\right) \delta_{\mathrm{H}} 8.02-7.94(\mathrm{~m}, 1 \mathrm{H}), 7.82(\mathrm{~d}, J$ $=3.7 \mathrm{~Hz}, 1 \mathrm{H}), 7.48(\mathrm{~d}, J=7.3 \mathrm{~Hz}, 1 \mathrm{H}), 7.30$ (d, $J=7.8 \mathrm{~Hz}, 1 \mathrm{H})$, 5.62-5.50 (m, 2H), 5.36-5.27 (m, 1H), 5.03-4.90 (m, 2H), $4.82(\mathrm{~s}$, $1 \mathrm{H})$, 4.25-4.10 (m, $1 \mathrm{H}), 3.21-3.14(\mathrm{~m}, 1 \mathrm{H}), 2.99-2.90(\mathrm{~m}, 1 \mathrm{H})$, 2.88-2.75 (m, 1H), 2.51 (s, 3H), 2.42-2.36 (m, 1H), 2.22-2.16 (m, $1 \mathrm{H}), 2.11(\mathrm{~s}, 3 \mathrm{H}), 2.03-1.95(\mathrm{~m}, 1 \mathrm{H}), 1.87-1.63(\mathrm{~m}, 3 \mathrm{H}) ;{ }^{13} \mathrm{C}$ NMR $\left(100 \mathrm{MHz}, \mathrm{CDCl}_{3}\right) \delta_{\mathrm{C}} 170.9,170.4,147.8,147.4,147.0,140.8$, 134.3, 132.0, 129.9, 127.8, 125.4, 124.9, 114.8, 114.5, 82.9, 74.6, 50.7, 45.2, 43.8, 36.6, 32.3, 29.0, 21.3, 21.2; HRMS (ESI) calcd for $\mathrm{C}_{24} \mathrm{H}_{25} \mathrm{O}_{6} \mathrm{NNa}[\mathrm{M}+\mathrm{Na}]^{+}$446.1574, found 446.1571.

\section{Biology}

Anticancer studies. Compounds were dissolved in DMSO (Sigma) to prepare $50 \mathrm{mM}$ concentrations stock solutions. All the further dilutions were also made in DMSO. During the treatment, the final concentration of DMSO was maintained $<0.02 \%$.

Antibodies. Anti-caspase 9 and anti-caspase 3 antibodies were purchased from Cell Signaling and anti- $\alpha$-tubulin antibody was procured from Sigma, aoat anti-rabbit HRP conjugated secondary antibody was purchased from Bio-Rad, and goat antimouse HRP conjugated secondary antibody was purchased from Cell Signaling.

Cell culture. Breast cancer cell line MCF7 was grown in DMEM (GIBCO), MBA-MB-231 in RPMI (GIBCO) with 10\% FBS, $100 \mathrm{U} \mathrm{mL}^{-1}$ penicillin and $100 \mu \mathrm{g} \mathrm{mL}^{-1}$ streptomycin and MCF10A in DMEM/F12 (Gibco) containing, horse Serum (10\% final), EGF (20ng ml $\left.{ }^{-1}\right)$, hydrocortisone $\left(0.5 \mathrm{mg} \mathrm{mL}^{-1}\right)$, cholera toxin $\left(100 \mathrm{ng} \mathrm{mL} \mathrm{m}^{-1}\right)$, insulin $\left(10 \mu \mathrm{g} \mathrm{mL}^{-1}\right)$ and penicillin/ streptomycin mix $(1 \mathrm{~mL} / 100 \mathrm{ml})$ at $37{ }^{\circ} \mathrm{C}$ in a humid, $5 \% \mathrm{CO}_{2}$ regulated incubator.

Growth inhibition by cytotoxicity assay. The cytotoxic effect of the compounds was determined using MTT (3-(4,5 dimethylthiazol-2-yl)-2-5 diphenyltetrazolium bromide) assay. Cells were seeded $\left(4 \times 10^{3}\right.$ per well $)$ in 96 well plates. After 24 hours of seeding, cells were exposed with varying concentrations $(0-100 \mu \mathrm{M})$ of respective compounds for 48 hours in triplicates. Then, MTT solution $\left(20 \mu \mathrm{L}\right.$ of $5 \mathrm{mg} \mathrm{mL}^{-1}$ stock for each well of 96 well plate) was added and further incubated for 3.5 hours in humid $5 \% \mathrm{CO}_{2}$ incubator. Media containing MTT solution was then replaced by MTT solvent (iso-propanol, $\mathrm{HCl}$ and Triton X-100), incubated for $15 \mathrm{~min}$ at room temperature with gentle shaking for complete dissolution of Formazan. Absorbance was measured at $570 \mathrm{~nm}$ using a Thermo Scientific
Multiskan G0 Elisa plate reader. All experiments were carried out at least in triplicate, and the percentage of viable cells was calculated as the mean with respect to the controls.

Western blot analysis. The cells were harvested, washed with $1 \times$ PBS and were lysed in lysis buffer (50 mM Tris pH 7.4, $5 \mathrm{mM}$ EDTA, $250 \mathrm{mM} \mathrm{NaCl}, 10 \mathrm{mM}$ sodium fluoride, $0.5 \mathrm{mM}$ sodium orthovanadate and $0.5 \%$ Triton X100) with $100 \mu \mathrm{L}$ lysis buffer per $35 \mathrm{~mm}$ cell culture plate. The lysate was incubated on ice for 20 minutes followed by centrifugation at $16000 \times g$ for 20 minutes at $4{ }^{\circ} \mathrm{C}$. The supernatant was collected, and the protein content was estimated by Bradford method using bovine serum albumin as a standard. The protein samples were prepared in $1 \times$ Laemmlli buffer and boiled for 5 minutes. The protein samples were then resolved by SDS-PAGE and transferred onto polyvinylidene fluoride membrane (Merck Millipore, Billerica, MA, USA). Skimmed milk (3\%) in 0.05\% Tween (TBST) was used for blocking the membrane for $1 \mathrm{~h}$. The membrane was then washed and incubated with the respective primary antibodies at $4{ }^{\circ} \mathrm{C}$ for overnight. The membrane was then washed thrice with TBST and incubated with respective HRP conjugated secondary antibody. Protein bands were detected using the Super Signal West Pico substrate (Thermo Scientific).

Cell cycle analysis by fluorescence-activated cell shortening (FACS). Cells were seeded one-day prior the treatment of compounds. Next day cells were incubated with and without selected compounds for $24 \mathrm{~h}$ and were then collected for FACS analysis. Propidium iodide staining was performed for the total DNA content of the cells. Briefly, the cells were washed with $1 \times$ PBS, trypsinized and then spin down at $3000 \times g$ for 2 minutes at $4{ }^{\circ} \mathrm{C}$. The cell pellet obtained was fixed and permeabilized using $900 \mu \mathrm{L}$ of $95 \%$ chilled ethanol, which was added dropwise along with continuous vortexing. The cells were then stored overnight at $4{ }^{\circ} \mathrm{C}$. The fixed cells were then pelleted at $3000 \times g$ for 2-3 minutes. The supernatant was discarded, and the pellet was washed twice with $1 \times$ PBS. The pellet was dissolved and stained with $1 \mathrm{~mL}$ staining solution $(900 \mu \mathrm{L} 1 \times$ PBS, $2 \mathrm{mM}$ $\mathrm{MgCl}_{2}$ ), $50 \mu \mathrm{L}$ propidium iodide stock solution $\left(5 \mathrm{mg} \mathrm{mL}{ }^{-1}\right.$ of $1 \times$ PBS) $50 \mu \mathrm{L}$ RNase stock solution ( $\left.1 \mathrm{mg} \mathrm{mL}^{-1}\right)$ and incubated at $37{ }^{\circ} \mathrm{C}$ for 20 minutes. Cells were then passed through cell strainers and proceed for FACS accusation on BD FACS Calibur. The data were then analyzed using Cell Quest pro software.

DNA fragmentation assay. DNA fragmentation assay was done after treating MCF7 cells with respective compounds as per the protocol described previously. ${ }^{15}$ The fragmentation ladder of the DNA was observed on a $2 \%$ agarose gel.

Immunostaining. The cells were grown on a cover slip as a monolayer overnight. The cells were then exposed with respective compounds at $\mathrm{IC}_{50}$ concentration and incubated for 12 hours. The cells on coverslips were fixed in $3.7 \%$ formaldehyde for 20 minutes in the dark at room temperature. The cover slips were washed 2-3 times with $1 \times$ PBS. The cells were then permeabilized by $0.5 \%$ Tween- 20 at room temperature for 30 minutes and then washed with PBS for 4 times. The permeabilized cells were blocked with $3 \%$ BSA followed by staining with $\alpha$-tubulin (Sigma) in 3\% BSA solution for $1 \mathrm{~h}$ at room temperature. The cells were washed with $1 \times$ PBS 5 times and then stained with ALEXA Flour 594 conjugated secondary 
antibody for $1 \mathrm{~h}$ and then washed with $1 \times$ PBS for 5 times. Finally, DNA was stained with Hoechst and coverslips were mounted on slides in mounting media $\left(8 \mathrm{mg} \mathrm{mL}^{-1}\right.$ DABCO in $80 \%$ glycerol and 20\% PBS).

\section{Conflicts of interest}

The authors declare no competing interests.

\section{Acknowledgements}

Generous financial support received from Science and Engineering Research Board (SERB), Department of Science \& Technology, Government of India (SR/S1/OC-02/2011) is gratefully acknowledged. Authors are grateful to Dr K. Kumaravel, Department of Marine Biotechnology, Centre of Advanced Study in Marine Biology, Annamalai University, Parangipettai-608502, Tamil Nadu for the collection of the plant material from Kolli Hills, Tamilnadu. Authors thank Prof. Dr N. Parthasarathy, Department of Ecology and Environmental Sciences, Pondicherry University, India for the taxonomic identification of the plant material. Authors are also grateful to Prof. Dr G. N. Krishna Kumari, Department of Medicinal Chemistry, Sri Ramachandra College of Biomedical Sciences, Technology and Research, Porur, Chennai for an authentic sample of zaluzanin D. Authors wish to thank Dr Rajesh G. Gonnade, Principle Scientist, Centre for Material Characterization, CSIR-NCL, Pune for his kind help with X-ray crystallography of one of our samples. E.K.A. and N.A.G. are grateful to the University Grants Commission (UGC), New Delhi for the award of their Senior Research Fellowships.

\section{Notes and references}

1 (a) G. M. Cragg, D. J. Newman and K. M. Snader, J. Nat. Prod., 1997, 60, 52-60; (b) D. J. Newman, G. M. Cragg and K. M. Snader, J. Nat. Prod., 2003, 66, 1022-1037; (c) M. Gordaliza, Clin. Transl. Oncol., 2007, 9, 767-776; (d) D. J. Newman and G. M. Cragg, J. Nat. Prod., 2007, 70, 461477; (e) A. L. Harvey, Drug Discovery Today, 2008, 13, 894901; (f) D. J. Newman and G. M. Cragg, J. Nat. Prod., 2012, 75, 311-335; $(g)$ E. C. Barnes, R. Kumar and R. A. Davis, Nat. Prod. Rep., 2016, 33, 372-381.

2 (a) G. W. Wang, J. J. Qin, X. R. Cheng, Y. H. Shen, L. Shan, H. Z. Jin and W. D. Zhang, Expert Opin. Invest. Drugs, 2014, 23, 317-345; (b) M. H. R. Amorim, R. M. Gil da Costa, C. Lopes and M. M. Bastos, Crit. Rev. Toxicol., 2013, 43, 559-579; (c) A. Ghantous, H. Gali-Muhtasib, H. Vuorela, N. A. Saliba and N. Darwiche, Drug Discovery Today, 2010, 15, 668-678; (d) M. Tanasova and S. J. Sturla, Chem. Rev., 2012, 112, 3578-3610; (e) I. Merfort, Curr. Drug Targets, 2011, 12, 1560-1573; (f) A. Janecka, A. Wyrębska, K. Gach, J. Fichna and T. Janecki, Drug Discovery Today, 2012, 17, 561-572; (g) E. Rodriguez, G. H. N. Towers and J. C. Mitchell, Phytochemistry, 1976, 15, 1573-1580; (h) A. K. Picman and G. H. N. Towers, Biochem. Syst. Ecol., 1983, 11, 321-327; (i) A. K. Picman, Biochem. Syst. Ecol.,
1986, 14, 255-281; (j) R. R. Kitson, A. Millemaggi and R. J. Taylor, Angew. Chem., Int. Ed., 2009, 48, 9426-9451; (k) A. K. Bhattacharya and R. P. Sharma, Heterocycles, 1999, 51, 1681-1745.

3 https://en.wikipedia.org/wiki/Vernonia.

4 (a) A. Bordignon, M. Frédérich, A. Ledoux, P. E. Campos, P. Clerc, T. Hermann, J. Quetin-Leclercq and E. Cieckiewicz, Nat. Prod. Res., 2017, 1-4; (b) C. Zdero, F. Bohlmann and G. M. Mungai, Phytochemistry, 1990, 29, 3668-3669; (c) A. M. Marzouk and O. B. Abd Elhalim, Nat. Prod. Res., 2016, 30, 741-749; (d) C. N. S. Antonio, B. d. S. Elnatan and O. dos S. F. Raquel, J. Med. Plants Res., 2015, 9, 838-850; (e) U. J. Youn, E. J. Park, T. P. Kondratyuk, C. J. Simmons, R. P. Borris, P. Tanamatayarat, S. Wongwiwatthananukit, O. Toyama, T. Songsak and J. M. Pezzuto, Bioorg. Med. Chem. Lett., 2012, 22, 5559-5562; (f) N. Kimani, J. Matasyoh, M. Kaiser, R. Brun and T. Schmidt, Molecules, 2017, 22, 597; $(g)$ A. Chea, S. Hout, C. Long, L. Marcourt, R. Faure, N. Azas and R. Elias, Chem. Pharm. Bull., 2006, 54, 1437-1439; (h) J. C. Chukwujekwu, C. A. Lategan, P. J. Smith, F. R. Van Heerden, J. Van Staden and S. Afr, J. Bot., 2009, 75, 176179; (i) U. J. Youn, G. Miklossy, X. Chai, S. Wongwiwatthananukit, O. Toyama, T. Songsak, J. Turkson and L. C. Chang, Fitoterapia, 2014, 93, 194-200; (j) A. Sinisi, E. Millán, S. M. Abay, A. Habluetzel, G. Appendino, E. Muñoz and O. Taglialatela-Scafati, J. Nat. Prod., 2015, 78, 1618-1623; ( $k$ ) R. B. Williams, A. Norris, C. Slebodnick, J. Merola, J. S. Miller, R. Andriantsiferana, V. E. Rasamison and D. G. I. Kingston, J. Nat. Prod., 2005, 68, 1371-1374; (l) N. J. Toyang, H. K. Wabo, E. N. Ateh, H. Davis, P. Tane, L. B. Sondengam, J. Bryant and R. Verpoorte, J. Ethnopharmacol., 2013, 146, 552-556; (m) N. J. Toyang, H. K. Wabo, E. N. Ateh, H. Davis, P. Tane, L. B. Sondengam, J. Bryant and R. Verpoorte, J. Ethnopharmacol., 2013, 146, 552-556; (n) O. Kos, V. Castro, R. Murillo, L. Poveda and I. Merfort, Phytochemistry, 2006, 67, 62-69; (o) W. G. Padolina, H. Yoshioka, N. Nakatani, T. J. Mabry, S. A. Monti, R. E. Davis, P. J. Cox, O. A. Sim, W. H. Watson and I. B. Wu, Tetrahedron, 1974, 30, 11611170; (p) C. A. Catalán, D. I. De Iglesias, J. Kavka, V. E. Sosa and W. Herz, Phytochemistry, 1988, 27, 197-202; (q) A. Bardón, N. I. Kamiya, C. A. D. P. De Léon, C. A. Catalán, J. G. Díaz and W. Herz, Phytochemistry, 1992, 31, 609-613; (r) L. Zhang, Y. L. Shao, L. Hua, Y. Li, S. H. Hussain, M. Arfan and K. Gao, Phytochem. Lett., 2014, 7, 14-18; (s) F. Bohlmann, C. Zdero, R. M. King and H. Robinson, Phytochemistry, 1982, 21, 695-699; $(t)$ C. Kraft, K. Jenett-Siems, K. Siems, J. Jakupovic, S. Mavi, U. Bienzle and E. Eich, Phytother. Res., 2003, 17, 123-128; (u) I. Ganjian, I. Kubo and P. Fludzinski, Phytochemistry, 1983, 22, 2525-2526; (v) B. Mompon and R. Toubian, Tetrahedron, 1976, 32, 2545-2548; (w) G. Roos, H. Prawat, C. U. Walter, I. Klaiber, B. Vogler, J. H. Guse and W. Kraus, Planta Med., 1998, 64, 673-674; $(x)$ T. Ito, S. Aimaiti, N. N. Win, T. Kodama and H. Morita, Bioorg. Med. Chem. Lett., 2016, 26, 3608-3611. 
5 (a) J. Jakupovic, S. Banerjee, V. Castro, F. Bohlmann, A. Schuster, J. D. Msonthi and S. Keeley, Phytochemistry, 1986, 25, 1359-1364; (b) A. B. Aliyu, N. A. Koorbanally, B. Moodley, P. Singh and H. Y. Chenia, Phytochemistry, 2016, 126, 23-33; (c) A. B. Aliyu, B. Moodley, H. Chenia and N. A. Koorbanally, Phytochemistry, 2015, 111, 163-168; (d) N. Kimani, J. Matasyoh, M. Kaiser, R. Brun and T. Schmidt, Molecules, 2018, 23, 248; (e) L. Jakupovic, D. A. Gage, F. Bohlmann and T. J. Mabry, Phytochemistry, 1986, 25, 1179-1183; (f) H. Buskuhl, F. L. de Oliveira, L. Z. Blind, R. A. de Freitas, A. Barison, F. R. Campos, Y. E. Corilo, M. N. Eberlin, G. F. Caramori and M. W. Biavatti, Phytochemistry, 2010, 71, 1539-1544; $(g)$ S. M. Kupchan, R. J. Hemingway, A. Karim and D. Werner, J. Org. Chem., 1969, 34, 3908-3911; (h) J. Jakupovic, C. Zdero, R. Boeker, U. Warning, F. Bohlmann and S. B. Jones, Eur. J. Org. Chem., 1987, 111-123; (i) T. J. Mabry, Z. Abdel-Baset, W. G. Padolina and S. B. Jones Jr, Biochem. Syst. Ecol., 1975, 2, 185-192; (j) A. Koziol, L. Mroczko, M. Niewiadomska and S. Lochyński, Polish Journal of Natural Sciences, 2017, 32, 495-511; (k) A. Bardón, C. A. Catalán, A. B. Gutiérrez and W. Herz, Phytochemistry, 1990, 29, 313-315; (l) F. Tsichritzis, K. Siems, J. Jakupovic, F. Bohlmann and G. M. Mungai, Phytochemistry, 1991, 30, 3808-3809; ( $m$ ) S. M. Kupchan, R. J. Hemingway, D. Werner, A. Karim, A. T. McPhail and G. A. Sim, J. Am. Chem. Soc., 1968, 90, 3596-3597; (n) M. Jisaka, H. Ohigashi, K. Takegawa, M. A. Huffman and K. Koshimizu, Biosci., Biotechnol., Biochem., 1993, 57, 833-834; (o) M. Jisaka, M. Kawanaka, H. Sugiyama, K. Takegawa, M. A. Huffman, H. Ohigashi and K. Koshimizu, Biosci., Biotechnol., Biochem., 1992, 56, 845-846.

6 R. R. A. Kitson, A. Millemaggi and R. J. K. Taylor, Angew. Chem., Int. Ed., 2009, 48, 9426-9451.

7 (a) N. J. Lawrence, A. T. McGown, J. Nduka, J. A. Hadfield and R. G. Pritchard, Bioorg. Med. Chem. Lett., 2001, 11, 429-431; (b) S. K. Srivastava, A. Abraham, B. Bhat, M. Jaggi, A. T. Singh, V. K. Sanna, G. Singh, S. K. Agarwal, R. Mukherjee and A. C. Burman, Bioorg. Med. Chem. Lett., 2006, 16, 4195-4199; (c) S. Neelakantan, S. Nasim, M. L. Guzman, C. T. Jordan and P. A. Crooks, Bioorg. Med. Chem. Lett., 2009, 19, 4346-4349; (d) S. Nasim and P. A. Crooks, Bioorg. Med. Chem. Lett., 2008, 18, 3870-3873; (e) D. R. Hwang, Y. S. Wu, C. W. Chang, T. W. Lien, W. C. Chen, U. K. Tan, J. T. A. Hsu and H. P. Hsieh, Bioorg. Med. Chem., 2006, 14, 83-91; (f) S. G. Klochkov, S. V. Afanas'eva, A. N. Pushin, G. K. Gerasimova, N. K. Vlasenkova and Y. N. Bulychev, Chem. Nat. Compd., 2009, 46, 817-823; $(g)$ K. H. Lee, H. Furukawa and E. S. Huang, J. Med. Chem., 1972, 15, 609-611; (h)
E. Hejchman, R. D. Haugwitz and M. Cushman, J. Med. Chem., 1995, 38, 3407-3410; (i) N. R. Unde, S. V. Hiremath, G. H. Kulkarni and G. R. Kelkar, Tetrahedron Lett., 1968, 9, 4861-4862; (j) J. R. Woods, H. Mo, A. A. Bieberich, T. Alavanjac and D. A. Colby, J. Med. Chem., 2011, 54, 7934-7941.

8 J. R. Woods, H. Mo, A. A. Bieberich, T. Alavanjac and D. A. Colby, Med. Chem. Commun., 2013, 4, 27-33 and references cited therein.

9 (a) A. K. Bhattacharya, D. C. Jain, R. P. Sharma, R. Roy and A. T. McPhail, Tetrahedron, 1997, 53, 14975-14990; (b) A. K. Bhattacharya, M. Pal, D. C. Jain, B. S. Joshi, R. Roy, U. Rychlewska and R. P. Sharma, Tetrahedron, 2003, 59, 2871-2876; (c) A. K. Bhattacharya and K. C. Rana, Indian J. Chem., 2013, 52B, 901-903; (d) A. K. Bhattacharya, H. R. Chand, J. John and M. V. Deshpande, Eur. J. Med. Chem., 2015, 94, 1-7; (e) T. R. Valkute, M. Arkile, D. Sarkar and A. K. Bhattacharya, Planta Medica International Open, 2016, 3, e55-e59.

10 (a) G. N. Krishna Kumari, S. Masilamani, M. R. Ganesh and S. Aravind, Phytochemistry, 2003, 62, 1101-1104; (b) G. N. Krishna Kumari, S. Masilamani, M. R. Ganesh, S. Aravind and S. R. Sridhar, Fitoterapia, 2003, 74, 479-482.

11 Crystallographic data (excluding structure factors): CCDC1525170 contains the supplementary crystallographic data for this paper.

12 H. Matsuda, T. Kageura, Y. Inoue, T. Morikawa and M. Yoshikawa, Tetrahedron, 2000, 56, 7763-7777.

13 (a) C. Han, F. J. Barrios, M. V. Riofski and D. A. Colby, J. Org. Chem., 2009, 74, 7176-7179; (b) P. R. R. Vadaparthi, C. P. Kumar, K. Kumar, A. Venkanna, V. L. Nayak, S. Ramakrishna and K. S. Babu, Med. Chem. Res., 2015, 24, 2871-2878; (c) E. E. Shul'ts, A. V. Belovodskii, M. M. Shakirov and G. A. Tolstikov, Russ. Chem. Bull., 2012, 61, 1975-1985; (d) A. S. Kihkentayeva, E. E. Shults, Y. V. Gatilov, S. S. Patrushev, S. Karim, G. A. Atazhanova and S. M. Adekenov, Chem. Heterocycl. Compd., 2016, 52, 788-796; (e) Y. H. Ding, H. X. Fan, J. Long, Q. Zhang and Y. Chen, Bioorg. Med. Chem. Lett., 2013, 23, 6087-6092.

14 I. P. Beletskaya and A. V. Cheprakov, Chem. Rev., 2000, 100, 3009-3066.

15 M. Herrmann, H. M. Lorenz, R. Voll, M. Grünke, W. Woith and J. R. Kalden, Nucleic Acids Res., 1994, 22, 5506-5507.

16 E. A. Slee, M. T. Harte, R. M. Kluck, B. B. Wolf, C. A. Casiano, D. D. Newmeyer, H. G. Wang, J. C. Reed, D. W. Nicholson, E. S. Alnemri, D. R. Green and S. J. Martin, J. Cell Biol., 1999, 144, 281-292.

17 S. Fuldaand and K. M. Debatin, Oncogene, 2006, 25, 47984811. 